\title{
EL OBISPO NICOLÁS VIDELA Y EL GENERAL BELGRANO. 1812-1819
}

\author{
POR \\ EMILIANo SÁnchez Pérez \\ Institutum Historicum Agustinianum
}

\begin{abstract}
RESUMEN
Con escasas excepciones, y estas no bien definidas y manifiestas, se ha ido transmitiendo por escrito y en la opinión pública, y entre historiadores, que Mons. Nicolás Videla del Pino cometió delito de lesa patria o de alta traición, por ser de sentimientos realistas y colaborar activamente con esta causa política. Este artículo documenta que fue, ante todo, un celoso pastor sin discriminar a quienes estaban en cada uno de los dos bandos.

Palabras ClaVe: Nicolás Videla del Pino Belgrano, Salta, realista, patriota, destierro, diezmos, ejército del Norte, Echenique. Deán Isasmendi, Superior Gobierno, Junta de Apelaciones, Francisco Malbrán.
\end{abstract}

\section{THE BISHOP NICOLÁS VIDELA AND THE GENERAL BELGRANO}

\begin{abstract}
With few exceptions, and these not well defined and gross, has been passed in writing and in public opinion and among historians, that Bishop Nicholas Videla del Pino committed a crime against the state or high treason, being realistic feelings and actively collaborate with the political cause. This article documents that was, above all, a good pastor without discriminating against those who were in each of the two sides.
\end{abstract}

KEY WORDS: Nicolás Videla, Realist, patriotic, Belgrano, Jump, exile, tithes, army of the North, Echenique. Isasmendi dean, Superior Government, Appeal committee, Francisco Malbrán. 


$\begin{array}{ll}\text { Recibido/Received } & 28-06-2013 \\ \text { Aceptado/Accepted } & 11-09-2013\end{array}$

\section{LOS ORÍGENES FAMILIARES}

Hay que decir que existe desacuerdo y excesiva oscuridad respecto a la fecha de nacimiento del primer obispo de Salta entre los escasos historiadores, que han reparado en este aspecto, algunos de ellos relevantes, por la importante documentación que usan. ${ }^{1}$ Sin querer ser exhaustivos, tenemos que reconocer que hay una gran diferencia entre los autores a la hora de fechar su nacimiento. Siguiendo los datos que nos ofrece su partida de bautismo, HAY que decir que Nicolás Videla del Pino nació en Córdoba el quince de Septiembre 1740, cuyos padres Juan José Videla y Pascuala del Pino, lo bautizaron en esa fecha en la santa Iglesia Catedral de Córdoba por el Deán Dr. D. Francisco Bazán de Pedraza, con licencia del Sr. Cura Rector, cuando era «de edad de ocho días».2

Tampoco es fortuita esta confusión sobre la fecha de su nacimiento, ya que el mismo Videla del Pino la facilitó. Por poner un solo ejemplo, en la defensa que hizo él mismo de su inocencia, durante el interrogatorio ordenado por la Soberana Asamblea del Año XIII y en mayo del mismo año, dice tener entonces setenta y seis años de edad, con lo que anticiparía su nacimiento a $1737 .{ }^{3} \mathrm{Su}$

${ }^{1}$ Nicolás Videla del Pino había nacido en Córdoba de Tucumán el 6 de diciembre de 1741 (ASV, Consultor, años 1802/1803, fol. 306v), Ritzler, Remigium, R. - Pirminium, S. 1968. Hierarchia Catholica, vol. 7: 330. Patavii: Typis et Sumptibus Domus Editorialis «Il Messaggero di S. Antonio» apud Basilicam S. Antonii. La fecha se afirma que nació en 1744 en DellaFerrera, N. 1996. Los Provisores de la Iglesia de Córdoba, Separata de Cuadernos de Historia, $\mathrm{N}^{\circ}$ 6, Córdoba. Esta fecha la recoge Cayetano Bruno, el gran especialista en búsqueda archivística, QUIEN refiere su nacimiento al año 1744, aunque extrañamente en él, sin CONSIGNAR referencia documental. Bruno, Cayetano. 1971. Historia de la Iglesia en la Argentina, vol. VII: 160. Buenos Aires: Editorial Don Bosco. Tenemos que decir que el mejor estudio sobre Nicolás Videla del Pino y sobre la diócesis de Salta, en su conjunto, es el que ofrece Cayetano Bruno en el volumen séptimo de su famosa y conocida obra. Hay otros varios estudios sobre Videla, realizados por solventes historiadores, y con buen aparato crítico, pero todos ellos se refieren a aspectos parciales de Videla.

${ }^{2}$ Archivo del Arzobispado de Córdoba, Libro 2 de Bautismos de la Catedral (1728-1778), f. 30. SE AGRADECEN estos datos a la gentileza de la Directora del Archivo del Arzobispado de Córdoba María Celina Audisio. A partir de ahora SE CITARÁ por AAC. Así es la partida de bautismo: «En quince de Septiembre de mil setecientos y cuarenta años, al Sr. Dr. D. Francisco Bazán de Pedraza, Deán de esta Santa Iglesia Catedral, de licencia del Sr. Cura Rector, bautizó, puso óleo y crisma a Nicolás, de edad de ocho días. Hijo legítimo de D. Juan José Videla y Da . Pascuala Pino. Fueron padrinos el General D. Bartolomé de Ugarte y $\mathrm{D}^{\mathrm{a}}$. Juana de Torres. Y para que conste, yo el infrascripto ayudante del Sr. Cura Rector Provisor y Vicario General D. Alonso Velasco Arjona. Lo firmé Pedro José de Sosa.» [rubricado].

${ }^{3}$ ARCHIVO GENERAL DE LA NACIÓN, Sala X, 4-7-2. A partir de ahora citaremos por AGN.

Hispania Sacra, LXVI

133, enero-junio 2014, 133-177, ISSN: 0018-215X, doi: 10.3989/hs.2013.049 
muerte tenemos que fecharla, como más segura, el 16 de Marzo de $1819 .{ }^{4}$ Sin embargo, aunque bastante en solitario, los datos de su partida de bautismo están bien claros.

Nicolás Videla del Pino pertenecía a la segunda rama de los Videla de la provincia de Cuyo, que inició Alonso Videla al casarse con Catalina Chacón, de cuyo matrimonio nacieron ocho hijos, y que tras varias generaciones, nació el que sería el primer obispo de Salta. ${ }^{5}$ Su padre era natural de Mendoza, y su madre de la misma ciudad de Córdoba. Siendo niño ingresó en el famoso Real Colegio de Nuestra Señora de Montserrat, de su ciudad natal, en cuya universidad estudió el joven Nicolás durante doce años, hasta doctorarse en filosofía y teología en 1764, cuando «se le confirieron públicamente los grados de Bachiller, Licenciado y Doctor en Sagrada Teología». ${ }^{6} \mathrm{Al}$ año siguiente recibió las órdenes mayores, presbiterado incluido.

Comenzó inmediatamente su ministerio sacerdotal, ejerciendo de teniente cura en la parroquia de Río Seco, durante un año, siendo después trasladado a Río Cuarto como Cura Excusador. Más tarde obtuvo por oposición el curato de los Llanos, de la jurisdicción de La Rioja, donde actuó durante catorce años «sin perdonar fatiga alguna» ${ }^{7}$ y donde erigió cinco capillas. Cerciorado el obispo de Córdoba, «del laudable celo y vigilancia» de Nicolás Videla, le concedió el obispo Moscoso y Peralta, facultades muy especiales hasta la «de dispensar en todos los impedimentos que podía su Ilustrísima». En este Curato puso especial empeño en la edificación de capillas, con todo lo necesario para sus servicios, a lo que contribuyó con la mayor parte de las expensas, no sólo con «su propio peculio, sino que también tuvo el trabajo verdaderamente grande de asistir a su construcción». ${ }^{8}$ Todo lo hizo con tanto acierto y buena conducta y «procedió con tanta conmiseración, que teniendo su curato tres pueblos de indios, que siempre pagaron sínodo, no les exigió ni medio real por esta razón».?

Su proverbial generosidad también se hizo sentir siendo profesor de Teología Moral en el Seminario de Loreto, por espacio de dos años, sin recibir sueldo alguno. Dicho Seminario había sido abierto por el obispo Argandoña el 18 de

${ }^{4}$ AGN, Sala X, 34-9-2, Exp. 3.866 y Sala X, 11-6-5.

${ }_{5}^{5}$ Martínez, P. S. 1961 «Mons. Nicolás Videla del Pino. Noticias acerca de su vida, obra y actitud frente a la Revolución», Archivum V: 353. Citando a José Pringles Guiñazú, Genealogías, fs. 64-65, le pone como madre a Antonia del Pino Machado, nombre que no coincide con el que da la partida de bautismo, que hemos citado.

${ }^{6}$ ARCHIVO GENERAL DE INDIAS, Relación de los méritos y servicios del Dr. D. Nicolás Videla del Pino, Madrid, 12 de julio de 1790, Buenos Aires 602. En adelante citaremos por AGI.

${ }^{7}$ Ídem.

${ }^{8}$ Ídem.

9 Ídem. 
Diciembre de $1752,{ }^{10}$ llegando a ser Rector del mismo Videla del Pino. ${ }^{11}$ Fue también Resolutor de casos morales, Promotor fiscal y Examinador Sinodal del obispado de Córdoba del Tucumán, por auto del obispo San Alberto del 27 de Junio de $1783,{ }^{12}$ acompañando también al gobernador intendente a los Llanos, al ser sus servicios sacerdotales de gran utilidad. Cuando en 1780 fue convocado concurso para la provisión de varios curatos, Videla del Pino consiguió el primer puesto, en el correspondiente al rectoral de Salta.

\section{Aspirantes al nUevo obispado de SALTA}

La creación de la diócesis de Salta, provocó distintas y encontradas opiniones, lo mismo que distintas alternativas para Videla del Pino. El entonces obispo del Paraguay, al que Mons. Tavella define como «muy ilustre por cierto, tanto por sus virtudes como por su talento organizador», ${ }^{13}$ era presumiblemente el sucesor de Ángel Mariano Moscoso en la diócesis de Córdoba, mientras que para la nueva de Salta, las preferencias se inclinaban hacia el Dr. D. Gregorio Funes. Pero ninguna de las dos suposiciones anuló las secretas y profundas aspiraciones del Deán Isasmendi.

El Deán Funes tenía poderosos padrinos apoyando su candidatura. Nada menos que el gobernador de Salta, lo mismo que el presidente de la Real Audiencia de Charcas, así lo habían pedido al Rey. ${ }^{14}$ La misma petición cursaron el Deán y Cabildo secular de Jujuy en oficio de 25 de Junio de $1806 .{ }^{15}$ El mismo Funes, entre sus muchas aspiraciones, no excluía esta mitra, como le escribía a su apoderado en Madrid D. Francisco Manuel Bedoya el 19 de octubre de $1803 .{ }^{16}$ Él mismo, en carta posterior, llegó a auto postularse como el único candidato a la mitra salteña, en esta auténtica carrera desenfrenada, que llegó a empañar sus propios méritos. En dicha carta, el Deán Funes remite a

${ }^{10}$ ARCHIVO DE LA CURIA ECLESIÁSTICA DE SALTA, El obispo Argandeña comunica la instalación y apertura del Seminario de Loreto, 18 de diciembre de 1852, Carpeta de aranceles eclesiásticos. En adelante citaremos por ACE, Salta.

${ }^{11}$ ACE, Salta, Expediente sobre la media anata del Deanato de la iglesia catedral de Córdoba. Córdoba 13 de enero de 1794, Carpeta de autos.

${ }^{12}$ ACE, Salta, Auto del Sr. San Alberto nombrando Examinador Sinodal al Sr. Videla, San Miguel de Tucumán, 27 de Junio de 1783, Carpeta de Autos.

${ }_{13}$ Seage, A. 1980. Tavella, primer Arzobispo de Salta, t. I Escritos, Salta 1980, pág. 212. Es la conferencia pronunciada ¿Po Seague? ¿por el por Mons. Tavella? en la Junta de Estudios Históricos de Mendoza, el 12 de Octubre de 1946, y publicada en el Boletín del Instituto de San Felipe y Santiago de Estudios Históricos de Salta, № 18, Salta, 1946.

${ }^{14}$ AGN, Carta del Deán Funes a D. Joaquín Juan de Flores, Córdoba 15 de abril de 1805, en Documentos de la Biblioteca Nacional, leg. 176, ms. 600.

15 AGI, Buenos Aires, 152.

${ }^{16}$ AGN, Buenos Aires, Documentos de la Biblioteca Nacional, leg. 176, ms. 571. 
su representante en Madrid el informe del nuevo gobernador, en el que se «se recomienda mi mérito para los obispados, y principalmente para el de Salta, siempre que se divida el actual. Yo observo por aquí que todo se ha puesto en movimiento con la noticia de estar próxima la división. El obispo del Paraguay hará cuanto pueda por salir del destino que le ha tocado, que, a la verdad, no es muy apetecible». Cita a continuación a varios candidatos, que en favor propio desaprueba Funes, terminando con la consigna a dicho representante Joaquín Juan de Flores «yo espero que usted nada omitirá que conduzca al buen éxito de mis pretensiones». ${ }^{17}$

Está claro que, para su elevación a la mitra cordobesa, el mayor obstáculo que veía Funes era el obispo del Paraguay, Nicolás Videla del Pino. Y desde luego, era una suposición prudente. La promoción de Videla a la diócesis paraguaya, por obra de Pío VII en 1802, había despertado un eco muy favorable a su favor en el Tucumán, de tal modo que se le veía como el indiscutible sucesor de Ángel Mariano Moscoso. El apoyo de los gobernadores intendentes de Córdoba y de Salta, no hacían más que transmitir el anhelo popular.

Pero a pesar de todas estas indiscutibles ayudas y positivas opiniones, las mayores alabanzas partían de los religiosos betlemitas de Córdoba. Estos pedían un prelado «docto, liberal, empeñoso en el alivio del público, caritativo con los pobres, y, en especial, con los enfermos, circunstancias que adornan el carácter distinguido del ilustrísimo señor Dr. D. Nicolás Videla del Pino, dignísimo obispo del Paraguay, con que se hizo apreciado de los sabios por su doctitud, asilo de los necesitados por su liberalidad, amado de las casas públicas por su empeño en sostenerlas, finalmente suspirado y aclamado de los pobres enfermos por su caridad [y] buen trato de estos últimos. Ayes y clamores son nuestras salas, de que somos testigos oculares». Más aún, había gobernado la diócesis durante nueve años, «con tanto pulso y tranquilidad, que cautivó todos los corazones de sus habitantes, de quines se hizo su dueño». ${ }^{18}$

Pero dado que «el hombre propone y Dios dispone», finalmente, la mitra de Córdoba, no coronó las sienes de ninguno de los dos claros aspirantes a ella, uno por sus méritos personales, que creía sobrados, y otro, por reclamo popular, que también los veía sobrados. ¿Cuál fue la causa de este imprevisto resultado? Al Deán Funes presumiblemente le perjudicaron informes que lo desfavorecían, y a Videla, porque su presencia pastoral se veía más rentable en Salta, por la seguridad que daba a la hora de organizar esta nueva diócesis.

Tampoco es descartable la necesidad que se veía de colocar en la importante sede cordobesa a un obispo de origen peninsular, como sucedió con Rodrigo

\footnotetext{
${ }^{17}$ AGN, Buenos Aires, Documentos de la Biblioteca Nacional, Leg. 176, ms. 571.

${ }^{18}$ AGI, Carta de los betlemitas de Córdoba al Rey, 22 de junio de 1805, Buenos Aires, 316.
} 
Antonio de Orellana. Quizá en su elección se tuvo muy presente la nota reservada, que el arzobispo San Alberto envió al ministro D. José Gálvez desde Charcas en 1787: «Siempre seré de dictamen no convenir ni a la religión ni al estado, que para obispados ni arzobispados se elijan sujetos nacidos y criados en estas tierras; porque por muy buenos que parezcan, y por acreditados que se hallen en talento y literatura, en los más de ellos son todas estas prendas muy superficiales, y en los pocos que no lo son, se hallan regularmente mezcladas con unas doctrinas nacionales y laxas, y con una aversión o desafecto natural a todo lo que es y sabe a España, que no pueden disimular sino con mucha violencia, y sólo mientras llegan a lograr los ascensos que les propone y facilita su ambición». ${ }^{19}$ Por otra parte, tampoco esta práctica había sido inusual a lo largo y ancho de toda la Colonia.

Por eso el Rey, siguiendo los dictámenes del obispo de Charcas y del Virrey Marqués de Sobremonte, desestimó todas las proposiciones contrarias a Videla y, en vista de la eficaz actividad desplegada por este en el Paraguay, decidió finalmente confiarle, sin más trámites, la organización de la nueva diócesis salteña. Ciertamente el Deán no se esperaba esta respuesta, que confirma el tono de su carta a su apoderado en Madrid: «Apenas vinieron las bulas para la erección del nuevo obispado de Salta dio cuenta al Rey la Cámara para saber si había de hacer consulta; y a poco tiempo de habérsele contestado que quedaba enterado su Majestad, se ha conferido la mitra al obispo del Paraguay, sin dar lugar a otra cosa; con lo cual hemos sido completamente burlados todos los que teníamos miras fundadas sobre el particular». ${ }^{20}$

Por fin, el nombramiento de Videla se formalizó el 7 de septiembre de $1806 .{ }^{21}$ La Real Cédula de presentación, está fechada en San Lorenzo del El Escorial el 27 de octubre del mismo año. ${ }^{22}$ Siguiendo este proceso su obligado curso, el 16 de noviembre, según decreto de la Sagrada Congregación Consistorial, encargaba el Rey a Videla, la erección de la diócesis y la redacción de sus correspondientes estatutos. Asimismo, el Rey le pedía que en la demarcación geográfica de sus límites diocesanos, obrase de acuerdo con los gobernadores intendentes de Córdoba y de Salta. ${ }^{23}$

El 7 de febrero de 1807, el nuncio apostólico en España D. Pedro Gravina, arzobispo de Nicea, ordenaba el proceso consistorial. Este se inició dos días después,${ }^{24}$ en el que el Papa junto con los cardenales, proclamó a Videla obispo,

\footnotetext{
${ }^{19}$ AGI, Charcas, 578.

${ }^{20}$ AGN, Buenos Aires, Leg. 259, ms. 3.723.

${ }^{21}$ AGI, Madrid 4 de Octubre de 1806, Buenos Aires 602.

${ }^{22}$ Archivio Segretto Vaticano, Acta Camerarii, vol. 50, ff. 395r. En adelante citaremos por ASV.

${ }^{23}$ AGI, Buenos Aires 602.

${ }^{24}$ ASV, Processus consistoriales, vol. 208, ff. 391ss.
} 
previo análisis de la documentación informativa pedida y obtenida de distintas personas, que lo conocían bien. En ella vertían sus opiniones, que en este caso debieron ser obligadamente positivas, para el desempeño de su cargo y misión episcopal salteña. El lunes 23 de marzo Pío VII autorizaba el traslado de Nicolás Videla del Pino a Salta, y simultáneamente confería la investidura canónica de Asunción del Paraguay a Fr. Pedro García de Panes, religioso franciscano traído de la diócesis de Palencia, en España. ${ }^{25}$

\section{Problemáticos inicios del obispo Nicolás Videla del Pino}

El 28 de marzo de 1806 se crea el obispado de Salta por la Constitución Apostólica Regalium Principum de Pío VII. Nacía, así, desmembrada de la diócesis de Córdoba, la de Salta, tercera de la actual Argentina. La elección de su primer obispo, Nicolás Videla del Pino, siguió los trámites habituales entonces. El Rey Carlos IV lo propone al Papa para ocupar dicha diócesis, que, tanto en este caso, como en los demás, era un puro trámite, pues por el Patronato Real y su derivado, el Vicariato Regio, era aceptado por el Papa sin más exigencias. El obispo Videla, antes de ser consagrado, tal como estaba establecido, juró in verbo sacerdotis tacto pectore, «que no contravendrían en tiempo alguno, ni por ninguna manera, al Real Patronato de nuestro soberano, y que antes bien lo guardará y cumplirá en todo y por todo llanamente y sin impedimento alguno. Que asimismo no impedirá ni estorbará el uso de la real jurisdicción, ni la cobranza de los derechos y rentas reales, que en alguna manera pertenecieren a su Majestad, ni los dos novenos que tan justamente tiene reservados en los diezmos de las iglesias de las Indias, y que antes bien ayudará para que los ministros, a quienes toca, los recojan llanamente y sin contradicción ninguna. Que hará las nominaciones, instituciones y colaciones a que está obligado, conforma al dicho Real Patronazgo». ${ }^{26}$

Videla, por su parte, para llevar a cabo un mejor servicio religioso en la Catedral, «trató de hacerlo creando de aumento dignidades», aumento que recibió la aprobación real. ${ }^{27}$ Pero aquí nace uno de los principales focos de fuerte

${ }^{25}$ ASV, $F c-A c$., vol. 50, f. 395 y 397.

${ }^{26}$ ACE, Salta, Juramento con arreglo a ley que deben prestar los obispos, Córdoba, 28 de julio de 1803, en Archivo de la Curia de Salta, Carpeta Videla del Pino. En adelante citaremos por ACE, Salta. Son varias las Cédulas Reales sobre este tema, lo mismo que la correspondencia con el Virrey Santiago Liniers, el anterior a Baltasar Hidalgo de Cisneros, en este Archivo.

${ }^{27}$ ACE, Salta, El Rey participa al Virrey de Buenos Aires su aprobación por todo lo obrado en el obispado de Salta, la erección de su Iglesia, visita de su obispado y otros puntos, en Carpeta comunicaciones del Gobierno, Cádiz 2 de marzo de 1811. Este oficio viene a nombre de Fernando VII, pero es «en su ausencia y cautividad, el Consejo de Regencia de España e Indias», que a la sazón estaba en Cádiz, el que realmente lo emite, Ídem. 
enemistad, y de graves consecuencias para el futuro de Videla del Pino. El Deán Vicente Anastasio Isasmendi y los canónigos José Miguel de Castro y Pedro de Arán y Morales, que tenías esas dignidades eclesiásticas por concesión real, y que Videla respetó, manifestaron al Virrey de Buenos Aires «los prejuicios que se seguían a ellos [...], de las disposiciones del citado obispo, en quien no suponían todo el lleno de las facultades de que hacía vos [el Virrey], con otras expresiones, que tendían a haceros creer, que dicho prelado abusaba de las que yo [el Rey] le tenía concedido». ${ }^{28}$ De resultas de esas acusaciones, el obispo se vio precisado a recurrir también al Virrey D. Baltasar Hidalgo de Cisneros, por dos veces consecutivas, «en defensa de las provisiones interinas, que era lo que había exaltado a los referidos Isasmendi y Castro, y enterádole en los motivos en que estaban fundadas sus disposiciones». ${ }^{29}$ Ambos tachaban de anticanónicas estas colaciones de Videla, cuando anticanónico había sido el reconocimiento de sus cargos por Videla, antes de la Erección de la Cátedral y Cabildo eclesiástico, presionado por ellos. En el fondo, lo que pretendían era que, al no haber más dotaciones, los únicos cargos serían los tres que recibieron ellos, interinamente y por elección real, con su consiguiente beneficio económico, que menguaba, precisamente, el incremento de los cargos hecho por Videla. Lo vemos por la contestación que les da el Virrey Cisneros, en nombre del Rey, retenido por Napoleón en Francia, al indicarles que no podía ser «el objeto de mis rectas intenciones el enriquecer a los ministros del santuario, sino sólo el asistirles con una competente congrua». ${ }^{30}$

Videla, no había cometido ninguna injusticia con ellos ni caído en ninguna ilegalidad, ya que este documento, que estamos citando ahora, tiene la aprobación real de su actuación, ${ }^{31}$ pero ellos tres se confabulan para intentar quedarse con la representación de todos los cargos y emolumentos económicos anejos. Como de este tipo de leyes, pocos eran los que estaban informados, los tres ofendidos se hacen fuertes en sus demandas, al contar con el favor «del gobernador interino de aquella ciudad, D. Nicolás Severo de Isasmendi, hermano del primero. Resistían el cumplimiento de lo determinado por el Reverendo obispo, con el pretexto de que estaban consignados a los tres prebendados, que habían obtenido mi real presentación, todas las rentas de la mesa capitular, ocasionando la circulación de esta idea, el mayor escándalo y desagrado en aquel público». ${ }^{32}$ Debido a este ambiente, Videla retrasó la Erección de la Catedral y creación del

\footnotetext{
${ }^{28}$ Ídem.

${ }^{29}$ Ídem.

${ }^{30}$ Ídem.

${ }^{31}$ Se conoce además AGN, El Fiscal de Buenos Aires ve conforme a ley los nombramientos hechos por Videla en la Erección de la Catedral, en Archivo General de la Nación, Sala X, 31-9-2, Buenos Aires, 16 de Diciembre de 1809. En adelante citaremos AGN.

32 Ídem.
} 
Cabildo eclesiástico, ${ }^{33}$ y promulgó su Carta Pastoral de $1809,{ }^{34}$ para tranquilizar a sus fieles. Pero a pesar de todas estas prudentes medidas cautelares, Videla no tuvo suerte, pues de resultas de ello, nació un poderoso foco de enemistad, decisivo en su posterior destierro. Es un ejemplo más de conflicto entre un nuevo Obispo foráneo y los poderes eclesiásticos locales. A Isasmendi le anulaba sus aspiraciones episcopales.

\section{INTERMINABLE BATALLA DE RECURSOS Y CONTRARRECURSOS}

Las dificultades para Videla no habían hecho más que empezar. Y, sin embargo, tenemos que reconocer que actuó con suma cautela y teniendo muy presente las costumbres seguidas por otras sedes: la metropolitana de México, Lima, Cuzco, Santiago de Chile y Tucumán, es decir, todas las de la América Colonial continental, «cuyo modelo siguió en el nombramiento de todos los cargos para el gobierno de la Iglesia de Salta». El Virrey las aprobó interinamente, «dadas las especiales circunstancias provocadas por la guerra», ${ }^{35}$ el 22 de Junio de 1809. Pero no solamente da cuenta al Virrey Santiago Liniers, sino también a la Metrópoli. ${ }^{36} \mathrm{Al}$ Rey le dice Videla del Pino que, «no pudiéndose abrir la Iglesia con sólo el número de tres que se hallaban nombrados por Vuestra Majestad y que se esperaban las reales presentaciones para las restantes sillas, estaría sin ejercicio ni servicio dicha Iglesia mucho tiempo, teniendo presente el ejemplar de la catedral erigida en la ciudad de Santiago del Estero, de la que esta se desmembra, sobre el nombramiento [...], dispuse ejecutarlo así. Para mayor seguridad, traté confidencialmente el asunto con Vuestro Virrey de Buenos Aires, a quien en tales apuros debí creer autorizado para una providencia interina, acordando dar cuentas, cada uno por su parte, a Vuestra Majestad, cuando el tiempo, la guerra y las circunstancias lo permitiesen». ${ }^{37}$

Esta prudente actuación, no impidió la grave desavenencia con el Deán Isasmendi y el canónigo Castro: «Pero di en el escollo de que a los tres días de mi arribo, sin haber publicado la Erección, ni impuéstose en ella ni tratado conmigo, el Deán nombrado D. Vicente Anastasio Isasmendi, puso a los dos canónigos provistos D. José Miguel Castro, [que] clandestinamente ocurrieron

${ }^{33}$ ACE, Salta, Erectio Ecclasiae Catedralis Saltensis. En Palacio Episcopal de Santiago del Estero, 14 de Abril de 1809. En la misma Carpeta existe traducción castellana de este documento, que Videla llama «Letras».

${ }^{34}$ ACE, Salta, Carta Pastoral de Videla, Carpeta Videla del Pino, Salta 9 de Diciembre de 1809.

${ }^{35}$ ACE, Salta, El obispo Videla da cuenta al Virrey Liniers del desempeño de su ministerio desde Abipones, Carpeta Videla del Pino, Santiago del Estero, 16 de Mayo de 1809.

${ }^{36}$ ACE, Salta, Carta de Videla al Rey sobre la colación de cargos en la diócesis de Salta, Carpeta Videla del Pino, 17 de Junio de 1809.

${ }^{37}$ Ídem. 
a Vuestro Virrey con las falsedades, calumnias e ignorancias que contiene su $[\ldots] \gg{ }^{38}$ Aquí termina este incompleto documento. A esto se sumaba «el conocimiento que tenía de la mala conducta de aquellos eclesiásticos y las frecuentes denuncias que diariamente le llegaban de sus continuos excesos, acreditados en las sumarias que les formó para justificarlos, [y que] le obligaron a suspender las provisión de sus prebendas, y a remover además al Deán del Provisorato, que le había concedido, en fuerza de unos informes subrepticios con [que] se sorprendió su buena fe»..$^{39}$ El problema estaba servido, pues además de negarles sus desmedidas aspiraciones, ahora se juntaba la separación del cargo, que el mismo Videla les había conferido anteriormente. El Obispo fue plenamente consciente, de que todas estas «ocurrencias de la Erección, tuvieron considerables transcendencias, que me acarrearon algunas enemistades particulares, que no han perdido ocasión de calumniarme, perseguirme y molestarme, por modos públicos y también clandestinos».$^{40}$ Más aún, su sobrino Francisco Malbrán pide al Presidente del Gobierno Central de Buenos Aires, que «Vuestra Excelencia se digne extender su protección a los eclesiásticos familiares del Rvdo. Obispo, a quienes se persigue y oprime en Salta, como a cómplices de su fuga, hallándose actualmente en la cárcel pública, su secretario el Dr. D. José Gabriel Echenique, cuando a Vuestra Excelencia es constante el objeto de su ocultación». ${ }^{41}$

No queremos que pase desapercibida la expresión «unos informes subrepticios con que se sorprendió su buena fe», ya que la opinión inicial de Videla, sobre el Deán Isasmendi, fue relevantemente laudatoria, por las virtudes intelectuales y morales de que creía estaba adornado.$^{42}$ Este cambio tan extremo de opinión, es debido, o bien a que sus anteriores conocimientos no eran tan precisos, $o$ a que, en estos años se produjo un lamentable cambio en el comportamiento del Deán Isasmendi, pues el resultado de estas dos opiniones tan dispares de Videla sobre el Deán Isasmendi, traen consigo, al tomar posesión del nuevo obispado,

${ }^{38}$ ACE, Salta, se da la circunstancia de que fue su hermano Nicolás Severo de Isasmendi, Intendente Gobernador y Capitán General de Salta, quién ordenó el 14 de agosto de 1809, el cumplimiento de la Cédula Real al Obispo Videla para que se le guarden los honores debidos como Prelado de Salta, Carpeta Documentos del Gobierno, Aranjuez, 25 de Mayo de 1807.

39 ACE, Salta, El Rey participa al Virrey [...].

${ }^{40}$ AGN, Carta de Videla al Gobierno Central sobre su proceso, Sala X, 4-7-2, Buenos Aires 21 de mayo de 1813 .

${ }^{41}$ AGN, Carta de Francisco Malbrán al Gobierno Central, Sala X, 4-7-2, Buenos Aires 11 de 1812.

42 AGN El obispo del Paraguay informa a Vuestra Majestad sobre la literatura y servicios del Dr. D. Vicente Anastasio Isasmendi, Cura Rector de la Capital de Salta, Sala IX, 31-9-2, 19 de diciembre de 1804. Entonces lo consideraba «digno y acreedor, no sólo de una Canonjía, sino también de cualquier dignidad, y aún Mitra, que sea del real agrado de Vuestra Majestad, pues creo desempeñará el ministerio muy en obsequio de Dios, servicio de Vuestra Majestad y bien espiritual y temporal de la Iglesia», y este informe, lo hacía «porque conocía bien al clero de Tucumán», Relación de méritos y servicios del Dr. D. Vicente Anastasio Isasmendi, en AGN, Sala IX, 31-9-2, 13 de Marzo de 1805, trae informes muy positivos de nuevo, sobre dicho Deán Isasmendi.

Hispania Sacra, LXVI

133, enero-junio 2014, 133-177, ISSN: 0018-215X, doi: 10.3989/hs.2013.049 
dos comportamientos ante el mismo personaje. Primero empieza nombrando a Isasmendi «por nuestro Provisor y Vicario General de este nuestro Obispado, por el tiempo que fuere de nuestra voluntad». ${ }^{43} \mathrm{~A}$ partir de aquí tenemos toda una serie de recursos por ambas partes. Isasmendi y Castro contra el Obispo Videla, con fuertes descalificaciones al mismo. En el primero de ellos, de 5 de Febrero de 1810, ambos prebendados, después de pedirle «que la erección de la Iglesia sea cumplida inmediatamente», solicitan al Virrey «se sirva declarar nulas, de ningún valor ni efecto las providencias de dignidades y canonjías, que, con notoria incompetencia y usurpación de autoridad, ejecutó aquel Reverendo Obispo». ${ }^{44}$ En un nuevo recurso, hacen un detallado comentario, de cada uno de los puntos, que Videla había expuesto al Virrey Cisneros: el aumento de oficios en la Catedral, el nombramiento los tres por el Rey, y la destitución que, de sus cargos, hizo Videla, rebatiendo punto por punto las acusaciones, en que se basó, sobre sus costumbres, conductas y formación intelectual. ${ }^{45}$ Ciertamente, tras varios recursos y con el apoyo que su hermano el Gobernador Intendente de Salta, obtuvieron, tras la consulta que el Virrey hizo al Consejo de Indias y a la Real Audiencia Pretorial, la concesión del Virrey, ordenando a Videla la suspensión de la provisión del aumento de cargos o sillas que hizo, «hasta que se resuelva por su Majestad lo conveniente [...], para que inmediatamente practique la apertura de la Iglesia Catedral, dando la colación y canónica institución al Deán y canónigos nombrados por su Majestad, evitando nuevas quejas y recursos [...], y encargándole reservadamente, así al Reverendo Obispo, como al Gobernador, que prescindiendo de las desavenencias, que han producido la diversidad de opiniones en este asunto, observen la mejor armonía, como tan indispensable en las presentes circunstancias, entre las autoridades, para la conservación de la tranquilidad pública». ${ }^{46}$ No es este un veredicto de ilegalidad de la actuación del obispo Videla, sino una medida cautelar en pro de la paz. Obtenida esta concesión de Buenos Aires, presentan Isasmendi y Castro un largo recurso al Cabildo de Salta «a efecto de que suspenda todo procedimiento en orden a colación y canónica institución a los por él [Videla] presentados, hasta tanto que la Suprema Junta Gubernativa, donde protestamos ocurrir, resuelva en el asunto, lo que tuviere conveniente». ${ }^{47}$

${ }^{43}$ AGN, Carta del Virrey Liniers a Isasmendi confirmando su nombramiento por el obispo Videla, Sala IX, 31-9-2, Buenos Aires 21 de Marzo de 1809; Ídem, Nombramiento del Deán Isasmendi por Videla, Sala IX, 31-9-2, Asunción del Paraguay, Santiago del Estero, 12 de Diciembre de 1808.

${ }^{44}$ AGN, Recurso del Deán Isasmendi y el Canónigo Castro al Virrey, Sala IX, 31-9-2, Buenos Aires 5 de Febrero de 1810.

${ }^{45}$ AGN, Carta de Isasmendi y Castro al Virrey Cisneros, Sala IX, 31-9-2, Salta 19 de Febrero de 1810.

${ }^{46}$ AGN, Decisión sobre los nuevos recursos de Isasmendi y Castro, Sala IX, 31-9-2, Buenos Aires, 26 de Febrero de 1810.

${ }^{47}$ AGN, Carta de Isasmendi y Castro al Cabildo de Salta sobre las colaciones de Videla, Sala IX, 31-9-2, Salta, 19 de Agosto de 1809. 
A las anteriores intervenciones, respondió Videla con una carta al Virrey Cisneros, en la que le informa que, cumpliendo con el mandato del Rey de someter a examen a los tres cargos, así lo hizo Videla, ofreciendo este resumen de todos los cargos que hizo contra ellos: «que se presentó sin recelo el canónigo Dr. D. Pedro Arán, quien desempeñó cumplidamente dicho examen, que sólo duró media hora. Los otros dos han resistido dicho examen con todas las demás obligaciones de su empleo y frívolas alegaciones, que verá Vuestra Excelencia, rebatí en mi auto hasta la evidencia». ${ }^{48}$

Si Isasmendi contaba con el apoyo de su hermano el Gobernador Intendente, Videla tenía tras de sí a todo el pueblo, como claramente comunica al Virrey Cisneros: «Pero quien creyera Excmo. señor, que dos sujetos únicos, cual es el Deán y otro canónigo D. Miguel de Castro, ambos patricios de este pueblo, contra el torrente universal de estas gentes (contra quienes no podré verter la menor queja sin injusticia), prevenidos del favor y paisanaje del Sr. Gobernador Interino, que lo es en su propia patria y hermano del Deán, hombre orgulloso y cuya ignorancia corre a par de su codicia, hayan pretendido alterar y aún resistir unas intenciones santas, benéficas, y que no tienen otro objeto que cumplir las cristianas determinaciones del Rey, en el incremento del culto divino, solemnidad de las funciones eclesiásticas y decoro de la santa Iglesia, con el afrentoso pretexto de estar consignadas todas las rentas de la Mesa Capitular a sólo tres, siendo constante del documento $\mathrm{n}^{\mathrm{O}} 4$, que no sólo con la renta consignada tiene para una vida cómoda y decente, sino que también les queda otra mitad que atesorar. El pueblo se halla absorto y conmovido, viendo privada su República de las ventajas que en lo espiritual y temporal esperaban con mi arribo. El Síndico Procurador, como consta del documento $\mathrm{n}^{\mathrm{o}} 3$, lo ha hecho presente al ilustre Cabildo, a efecto de que este me ofrece, para que despreciando tan frívolos y empeñosos obstáculos, publique la Erección, cumpla con las órdenes de su Majestad, erija el Seminario, establezca los estudios y demás obras piadosas, que tengo proyectadas». ${ }^{49}$

Para Videla estaba clara la motivación de los tres demandantes, que en nada respondían a sus manifestaciones oficiales contra el incremento de prebendas. Por eso no duda en escribir, que «los tres canónigos nombrados por el Rey, no sé por qué principio, se creyeron únicos acreedores y dueños de toda la Mesa Capitular, pues así me lo aseguró el Deán, a nombre de todos, sin más fundamento que haber mandado el Rey, que los diezmos de aquella nueva Iglesia, dispensando la Ley de Indias, se repartieran por tercias partes»..$^{50}$

\footnotetext{
${ }^{48}$ AGN, Carta de Videla al Virrey Cisneros justificando su actuación sobre el Deán Isasmendi y canónigo Castro, Sala IX, 31-9-2, Salta 6 de Abril de 1810.

49 AGN, Carta de Videla al Virrey Cisneros sobre los prebendados Isasmendi y Castro, Sala IX, 31-9-2, Salta, Septiembre de 1809.

${ }^{50} \mathrm{AGN}$, Carta de Videla al Gobierno informando de su actuación en la concesión de prebendas y dignidades al inicio de su episcopado, Sala X, 4-7-2, Buenos Aires 7 de Agosto de 1817.
}

Hispania Sacra, LXVI

133, enero-junio 2014, 133-177, ISSN: 0018-215X, doi: 10.3989/hs.2013.049 
No exageraba nada Videla con el anterior testimonio, pues el mismo Cabildo, en tres documentos, dejó claro el agradecimiento y alegría de los salteños, por el nombramiento y llegada de su Obispo ${ }^{51}$ ordenando «para perpetuar la memoria de los más benéficos actos, con motivo de la Erección de esta santa Iglesia Catedral, se estampe en el libro de Acuerdo, que su Señoría Ilustrísima el Sr. Dr. D. Nicolás Videla del Pino, tomó posesión de dicha Iglesia el día 15 del presente mes y año, en el que solemnemente hizo su entrada pública, con la magnificencia y esplendor que pudo proporcionar este ilustre Ayuntamiento, siendo la aclamación y vivas universales, por parte del pueblo, tan dignos de la alteza de su carácter, como merecidas por su ilustre persona». ${ }^{52} \mathrm{El}$ mismo Cabildo anunció al Virrey Cisneros las grandes esperanzas que tenía en la labor del obispo Videla. ${ }^{53}$

NOMBRAMIENTO DE ISASMENDI Y CASTRO Y SUSPENSIÓN DE SUS CARGOS

La segunda parte del duro enfrentamiento del Deán Isasmendi y del canónigo Castro con Videla, se refiere a la colación de sus cargos en la iglesia Catedral, en la que Videla cumplió escrupulosamente con lo establecido. Ambos se presentaron a Videla «exigiendo la colación interina providenciada por su Excelencia», a lo que Videla, «para evitar nuevas desazones a su persona y desaires a su dignidad, que dichos dos canónigos le han preparado, precavidos de su cierta protección, desde la colación que solicitan el día cuatro del corriente, en que se practica la función prevenida por su Excelencia [el Virrey Cisneros], con todas las ceremonias que ella envuelve, pero con la solemne protesta de su nulidad, y sin perjuicio de las resultas privativas a la Soberanía, en donde pende todo este asunto». ${ }^{54}$

En nota que sigue a este auto, Pedro Alcántara Arredondo, Secretario de Cámara, confirma que «se hizo en la iglesia Catedral, la función prevenida por su Excelencia, en su citada providencia de cinco de mayo, sin faltar un ápice de lo mandado, dando su Señoría Ilustrísima la colación y canónica institución de sus respectivas prebendas al Deán y Canónigo Castro, con formal protesta de su nulidad, y sin perjuicio de las resultas de la corte, donde pende todo este negocio». Videla, había nombrado ya en Junio de 1808, Juez Episcopal hacedor de diezmos al «Dr. D. Vicente Anastasio de Isasmendi, abogado de la Real Audiencia de Charcas y Deán electo de aquella Iglesia, [concurriendo] las cualidades de conciencia, letras e inteligencia, que nos hacen esperar desempeñará

${ }^{51}$ AGN, Sala IX, 31-9-2, Salta 23 de Agosto, 26 de Agosto y 2 de Septiembre de 1809

52 Ibídem, Salta 19 de agosto de 1809.

${ }^{53}$ Ibídem, Salta 2 de septiembre de 1809.

${ }^{54}$ ACE, Salta, Auto de Videla enviado al Virrey Cisneros sobre el Deán Isasmendi y el canónigo Castro, Carpeta Videla del Pino, Salta Junio de 1810. 
dicho oficio a toda nuestra satisfacción» ${ }^{55}$ Era un cargo que se renovaba cada dos años.

Videla informa ahora al Virrey Cisneros de la nulidad de este nombramiento, quien admite que Isasmendi «sin conocimiento de sus circunstancias, obtuvo por sorpresa la aprobación de este Superior Gobierno [y que] en esta inteligencia, manifiesto a Vuestra Señoría Ilustrísima [de Videla], que siempre que tenga causas justas, para remover al referido, puede usar de sus facultades justas, con sujeción a lo mandado en la última real cédula relativa a los Provisoratos». ${ }^{56}$

Isasmendi no tardó en enterarse de esta correspondencia, en su contra, de Videla con el Virrey Cisneros. Siempre gozó de buenos enlaces con Buenos Aires, para estar puntualmente informado de todo, como consta en la carta que dirige a Fray Tadeo Ocampo, a quien Isasmendi le concede la representación, tanto de él como del canónigo Castro, para que «incluyéndola en las sumarias e informes, remitidos por el Dr. Obispo, pueda el Fiscal, con vistas de unos y otros, prestar el voto consultivo, que se ha pedido, y a su Excelencia, librar con más acierto su providencia. Como es justamente a recelar, que su Ilustrísima no se descuide a remitir a la Junta Central igual informe y documentos, incluyo a Vuestra Ilustrísima los dichos, para que inmediatamente los pase a manos de nuestro agente». ${ }^{57}$ Con la misma finalidad, el canónigo Castro, envía otra carta. ${ }^{58}$

La presente documentación prueba que Videla no estaba bien informado, cuando emitió los primeros y muy laudatorios informes sobre Isasmendi, pues dos años después, Videla, recibe de Fernando VII, una carta en la que le dice que «en cartas de treinta y uno de Enero de mil ochocientos diez, me disteis cuenta, entre otras cosas, de las gravísimas causas que habíais tenido para no dar la posesión de la dignidad de Deán de esta iglesia a D. Vicente Anastasio de Isasmendi y al canónigo D. José de Castro, las cuales comprobasteis con las sumarias, que remitisteis de su desarreglada y escandalosa conducta, y de la oposición que hacía, que se verificase el aumento de prebendas, guiados sólo de su desmedido interés.», ${ }^{59}$ de lo que concluye, como ocurrió en el anterior documento del Virrey Cisneros, que «procedáis a tomar causa de Isasmendi y Castro,

55 ACE, Salta, Auto del Sr. Videla del Pino nombrando jueces hacedores de Diezmos, Carpeta Videla del Pino, Santiago del Estero 12 de Noviembre de 1808.

${ }^{56}$ ACE, Salta, Carta del Virrey Cisneros a Videla, Carpeta Videla del Pino, Buenos Aires 7 de Octubre de 1809

57 ACE, Salta, Carta del Dr. Isasmendi al Vicegeneral Fray Tadeo Ocampo, Carpeta Videla del Pino, Salta febrero de 1810.

${ }^{58}$ ACE, Salta Carta del Dr. José Miguel de Castro al Vicegeneral Fray Tadeo Ocampo, Carpeta de Videla del Pino, Salta 7 de Marzo de 1810.

${ }^{59}$ ACE, Salta, Carta de Fernando VII y en su ausencia y cautividad el Consejo de Regencia de España e Indias, autorizado interinamente por las Cortes Generales y Extraordinarias a Videla del Pino, Carpeta de Comunicaciones del Gobierno, Cádiz 2 de marzo de 1811.

Hispania Sacra, LXVI

133, enero-junio 2014, 133-177, ISSN: 0018-215X, doi: 10.3989/hs.2013.049 
conforme a derecho, y con las apelaciones que correspondan, las sentencies y determinéis en su vista, sobre ponerlos o no en posesión de la citada dignidad y canonjía respectiva, dándome cuenta de todo, con justificación, como os lo ruego». Esta opinión de Videla está en la antípoda de las anteriores.

Esta línea expositiva, puede crear el espejismo, de que se trataba de un enfrentamiento personal entre el Deán y Videla. Nada más ajeno a la realidad. El escrupuloso comportamiento legal de Videla lo supera. Prueba de ello es la carta colectiva de un grupo de presbíteros, que piden al Gobernador Intendente, «que sin pérdida de tiempo, mande aprehender, encarcelar y custodiar en los calabozos de esta real cárcel, a la persona del insurgente horroroso, ex Deán Dr. D. Vicente Anastasio Isasmendi». ${ }^{60}$ Entre las muchas y graves acusaciones que vierten, de las que dicen tener documentos probatorios, recogemos la referida al destierro de Videla: «Cualquiera que vea, como hemos visto, que este hombre se da y se confiere a sí mismo títulos pomposos y autoridades de que carece y que jamás merece, creerá firmemente que lo hace por un efecto de simplicidad. Pero no es así. Nadie ignora que por estos motivos fraguó, tramó [i], el destierro violento, de nuestro Ilustrísimo, atribuyéndole ante el insurgente Belgrano, ser este el mayor y más opuesto a la santa, justa y sagrada causa de la patria, que ellos defendían, y de haber correspondencia con el Sr. General en Jefe D. José Manuel de Goyeneche y demás Jefes del ejército real [...]. Estos aspectos y fantasmas, y otras acreditadas y públicas operaciones, exaltaron a Isasmendi, más y más ante los insurgentes de Buenos Aires y el comandante Belgrano, quien habiendo recibido un chasqui, que le hizo Isasmendi y su compañero el ex canónigo D. José Miguel de Castro, con los testimonios referidos, lograron que en día diez y siete de Abril del año pasado de mil ochocientos doce, se decretase el destierro y extrañamiento de nuestro Prelado, en el término de veinticuatro horas, y que sin la más mínima dilación, se pusiese en marcha para la capital de Buenos Aires». A Isasmendi lo califican de «hombre incorregible, ambiciosos de dignidad, de autoridad y mando. De mandarle la muerte [a Videla], para ser la esperanza futura de sucederle en la mitra».

\section{ORDEN DE DESTIERRO DE BELGRANO A VIDELA}

La precipitada y errónea decisión de Belgrano de desterrar a Videla, lo colocaba en un fuerte aprieto ante el pueblo salteño, consternado por su incomprensible y drástica decisión. Belgrano sabía de sobra, que esa decisión, en nada colaboraba a borrar la gran herida, que las graves y ofensivas actuaciones de

\footnotetext{
${ }^{60} \mathrm{ACE}$, Salta, Carta de varios presbíteros pidiendo se encarcele a Isasmendi, Carpeta querellas eclesiásticas, Salta 28 de febrero de 1814. En ese año las fuerzas realistas han reconquistado Chile y Salta.
} 
su primo Castelli, habían dejado en el sentimiento religioso de los fieles del Alto Perú. Pero el caso de Belgrano, resultaba aún más increíble, por sus públicas manifestaciones de católico, convicto y practicante, unidas a sus sentidas expresiones de afecto y veneración a Videla. Con sus dos bandos intentó aplacar al pueblo salteño ${ }^{61}$ Necesidades no le faltaban para ello. ${ }^{62}$ A pesar de estos intentos, Belgrano no resuelve la grave duda que provoca su carta al presbítero Echenique, a raíz de la «fuga» del obispo, que resultó sólo ocultación, pidiéndole hiciera todo lo posible por averiguar su paradero e invitarle a regresar» ${ }^{63}$ y concebida, en un lenguaje, totalmente opuesto e incompatible, con estos dos manifiestos. En el último de ellos afirma Belgrano: «cuánta fue mi sorpresa al leer cartas originales de Goyeneche, que acreditan la correspondencia que mantenía el Ilustrísimo Obispo con él». Tenemos que decir que dichas cartas no se encuentran en la abundante documentación conservada, ni su sobrino hace alusión a ellas, en los dos recursos de 14 de mayo y 10 de junio de $1812 .{ }^{64}$ Más aún, ordenado un análisis caligráfico de la firmas de las cartas de Goyeneche, por peritos, el dictamen fue que «opinaban no ser rúbricas de una misma mano». ${ }^{65} \mathrm{~A}$ esto, Videla incluso le negó valor, ya que «no constituye, por esto único, fuerza suficiente, y que no hay un perfecto legal convencimiento de infidencia y alta traición, porque se procede contra el acusado» ${ }^{66}$ Pero la conclusión del análisis

${ }^{61}$ AGN, Justificación de Belgrano ante el pueblo de Salta por el destierro de Videla, Sala X, 4-7-2, Salta 24 de Abril de 1812; Ibídem, Bando de Belgrano a los «pueblos de la Provincia de Salta», Sala X, 4-7-2, Cuartel General de Campo Santo 20 de octubre de 1812.

${ }^{62}$ AGN, Carta de su sobrino Francisco Malbrán a Videla, Sala X, 4-7-2, Buenos Aires 26 de Agosto de 1812, le dice que por carta que recibió de Tucumán, se informó que ese Cabildo y Sr. Gobernador, envió un correo a este Superior Gobierno, mediando para que Vuestra Señoría Ilustrísima, se quede por estos pueblos. De antemano tenía en mi poder otros clamores del Vicario, clero y otros curas de campaña de Santiago del Estero, y no les quise dar curso, porque el Superior Gobierno ha estado siempre firme en que Vuestra Señoría Ilustrísima debe venir a esta capital, y que así le conviene». Era de todos bien conocido el fuerte y decisivo influjo del clero.

${ }^{63}$ AGN, Carta de Belgrano al Dr. Luis Bernardo Echenique, Sala X, 4-7-2, Cuartel General de Campo Santo, 26 de Abril de 1812. Echenique le contesta, diciéndole que «me parece que su Ilustrísima, no ha fugado al campo enemigo, sino que se ha ocultado». Le habla de «las diligencias que se practican, para que este Ilustre Cabildo suplique a Usía por el indulto. [...]. Supuesto todo esto, me parecía muy conveniente, que Usía comunique el indulto, por conducto de este Ayuntamiento o del Gobernador de Provincia, en forma que haga fe. Que para unos efectos, y dos conductos, continúe Usía dispensando toda la piedad, que me hizo presente le concedería», Ibídem, Carta del Dr. Luís Bernardo Echenique al Gral. Belgrano, Sala X, 6-7-1 y Sala X, 4-7-2, Salta 1 de Mayo y 26 de Abril de 1812.Es inevitable preguntarse: ¿Por qué Belgrano, si estaba dispuesto al indulto, no lo indultó, cuando apareció el Obispo, y así anular su destierro? ¿Eran sinceros los sentimientos de Belgrano o eran promesas de político destinadas a no ser cumplidas?

${ }^{64}$ AGN, Recurso de Francisco Malbrán y Muñoz al Superior Gobierno de Buenos Aires contra el destierro de Videla del Pino, Sala X, 27-3-5, Buenos Aires 10 de junio de 1812; Ibídem, Recurso de Francisco Malbrán al Gobierno de las Provincias Unidas, Sala X, 4-7-2, Buenos Aires 14 de mayo de 1812.

${ }^{65}$ AGN; Proceso judicial a Videla, Sala X, 27-3-5, 22 de febrero de 1813.

${ }^{66}$ AGN, Proceso judicial a Videla, Sala X, 27-3-5, 22 de febrero de 1813.

Hispania Sacra, LXVI

133, enero-junio 2014, 133-177, ISSN: 0018-215X, doi: 10.3989/hs.2013.049 
pericial sí es importante, porque implica la existencia de firma falsificada. ¿Qué valor probatorio tenía entonces el punto principal de la acusación contra Videla de ser colaboracionista?

Pero aún tenemos otro documento, que juzgamos de especial valor. El Gobernador de Salta Dr. Domingo García, le escribe a Videla, que no sabe «si por oficio o por carta particular, me comunicó el Gral. Belgrano, que V. S. no había tenido correspondencia directa con Goyeneche, sino por medio del marqués de Yabi [...]». ${ }^{67}$ En la misma le añade que, «en el ataque de Tucumán perdió el Gral. Tristán toda su correspondencia, y se dijo públicamente se habían encontrado cartas de V. S. Yo vi parte de dicha correspondencia, pero no encontré cosa que se me pareciera, ni creo, hasta que lo vea». ${ }^{68}$

La singularidad de la carta de Belgrano a Echenique nos obliga a transcribirla completa, ya que la consideramos de un valor especial: ${ }^{69}$

Ud. es testigo de mis sentimientos, y cuanto me ha penetrado la fuga u ocultación del Ilustrísimo señor Obispo de esta diócesis. Veo con dolor las perjudiciales consecuencias que este procedimiento puede traer al honor de su Señoría Ilustrísima, y no menos al gobierno de su santa Iglesia, y a la cura de las almas de sus feligreses. Deseo remediar estos males, y quisiera que Ud. se tomase a su cargo hacer las indagaciones precisas, para que su Ilustrísima, vuelva a mis brazos, y vuelva a consolarnos. Que siento yo mismo los trabajos que pasará con su avanzada edad, sea cualesquiera el medio que hubiese adoptado. Aseguro a Ud, con toda la sinceridad de mi corazón, que hallará en mí, cuanto pueda desear y sea compatible con el honor y decoro de mi cargo. Le manifesté toda la confianza correspondiente a su carácter, dignidad y a los talentos y conocimientos que le adornan. Esa misma le dispensaré en todos los instantes, si Ud. llegase a tener, la suerte de encontrarlo. Clámele Ud., por Dios eterno, que no abandone su grey, que no me dé el sentimiento de verlo rodeado de soldados, y sí de sus familiares, y demás ministros que deben acompañarle. Suplico a Ud., que le exprese todo cuanto me ha oído, y de todas las demostraciones de sensibilidad, que ha presenciado en mí, por su dignidad, por su carácter y por sus años. Usted lleva todas mis facultades, y nadie será osado a perturbar cualesquiera de sus diligencias. Hágame Ud. este servicio, hágalo a su Señoría Ilustrísima, y hágalo a la Patria, que no se verá despedazada por sus detractores. Usted tendrá el reconocimiento de todos, y en particular de su siempre afectísimo amigo. Manuel Belgrano.

La contestación a los recursos de su sobrino Francisco Malbrán, fue que, «el agente concluye, por todo ello, que, atendido el mérito actual del sumario, debe imponerse al Reverendo Obispo de Salta, pena arbitraria, por medio de una confinación temporal y separación de su Diócesis, con total inhibición del ejercicio de su ministerio en ella, destinándosele, por tres años, a permanecer en

${ }^{67}$ AGN, Carta del Gobernador Domingo García a Videla, Sala X, 4-7-2, Familla, 9 de abril de 1813.

${ }^{68}$ Ídem.

${ }^{69}$ AGN, Carta de Belgrano al Dr. Luís Bernardo Echenique, Sala X, 4-7-2, Cuartel General de Campo Santo, 26 de abril de 1812. 
esta capital u otro paraje de las provincias, en que al paso que se consulte el castigo correspondiente, y con purga de lo que contra él ministra el proceso, sirva de segura precaución, de toda reincidencia, para lo sucesivo, en igual crimen». ${ }^{70}$ ¿Se cumplió en este proceso el principio de «in dubiis pro reo»? Está claro que no. Tampoco se cumplió «con el confinamiento temporal», sino definitivo hasta su muerte, y sin veredicto de culpabilidad. Sobre la actuación de Belgrano, su sobrino afirma que «estos procedimientos, que son formales penas y actos jurisdiccionales, no están dentro de la esfera del poder político, porque debieron seguirse a un verdadero juicio y a un pronunciamiento definitivo, que no ha podido recaer antes de formar el proceso y oír la defensa del Rvdo. Obispo. Son, por consiguiente, nulos, estrepitosos, expoliativos y refractarios del derecho de seguridad personal, que Vuestra Excelencia ha publicado, como el más auténtico monumento de su inmutable justificación». ${ }^{71}$

Ciertamente, son demasiados los interrogantes, para poder apreciar, en su justa medida, las razones profundas de esta actuación de Belgrano. ¿Qué valor le daba a la adhesión hecha por Videla a la Junta de Buenos Aires en el Cabildo abierto de Salta? ¿Y a la inclusión de la petición en la oración colecta de la misa «por la pía y santa causa de nuestra libertad»? ¿Cómo entender el que ordene salir hacia Buenos Aires, en el plazo de veinticuatro horas, a un anciano de setenta y tres años, a expensas de su magra economía, sin percibir los subsidios de sus rentas y con sus bienes incautados, sin aportarle cabalgaduras, etc., cuando en Tucumán o Santiago del Estero, también satisfacía las mismas medidas de seguridad? ¿Quién habilitó a Belgrano para esta jurisdicción política? Si tan dolido se muestra en la carta a Echenique, por el terror que le embargaba su hipotética huida a Perú, ¿por qué no ejerció el don de gracia, cuando voluntariamente apareció Videla?»Una carta enemiga, que indica un aviso vago, inconducente, sin circunstancias, sin verosimilitud, se ha hecho valer como prueba preferente a los solemnes testimonios, que desde la instalación del Gobierno Superior, ha dado aquel Prelado de su decidida adhesión a la causa de la Patria. ¿Es posible que un papel interceptado, sospechoso por su origen, por su autor y por sus calidades, incapaz de arrancar ni aún el ascenso extra judicial, se haya graduado por bastante para desbaratar la opinión de patriotismo, que el Rvdo. Obispo de Salta había merecido a los pueblos y al Superior Gobierno, con insignes servicios, con respetados hechos, con irrevocables pruebas? [...]. Unas tales y tan concluyentes pruebas, se desvirtúan y desaparecen al cotejo de un papel clandestino, ridículo y volado», que no justifican el «dejar una Iglesia huérfana y desolada, en tiempos calamitosos».

\footnotetext{
${ }^{70}$ AGN, Proceso judicial a Videla, Sala X, 27-3-5, 22 de febrero de 1813.

${ }^{71}$ AGN, Recurso de Francisco Malbrán y Muñoz contra el destierro a Buenos Aires [...].
} 
Otro foco de gran influjo y decisivo valor acusatorio contra Videla, está en Córdoba, donde Videla había ocupado altos cargos eclesiásticos antes de su elección para la diócesis de Asunción. Solamente queremos aportar dos documentos, importantes ambos, aunque la nómina de los mismos podría ser muy superior. Juan Ignacio Gorriti, en carta a Videla, le escribe: «Se me comunica la noticia de que al Gobernador de Córdoba se le han hecho informes contra la conducta de Vuestra Señoría Ilustrísima, sobre que en esa Villa [de Salta] está trabajando contra la causa de América. Disto mucho de creer que Vuestra Señoría Ilustrísima haya cometido semejante atentado, porque conozco lo que un celo indiscreto y acalorado, y también la malicia de cuantos hombres perversos, que hacen consistir el patriotismo en perjudicar a otros, y así temo que pueda este asunto llevarse adelante y que el jefe de la provincia tome alguna providencia, que sea sensible a Vuestra Señoría Ilustrísima. Y conviene que esté advertido del caso, para precaverse del resultado» ${ }^{72}$ Estamos en el año del Congreso de Tucumán. Los que se opusieron a la amnistía de Videla en el, fueron los representantes de Córdoba, como veremos más adelante.

El otro documento, del Deán Funes, de 16 de enero de 1806, tomado de una carta de Videla a Tomás Salustiano Gallardo, dice: «Habiendo la temeraria malignidad de ese Provisor Funes de calumniarme en el Supremo Consejo de las Indias, sin otro objeto que la osadía de abrir camino a sus ciegos y ambiciosos deseos de conseguir esa mitra, informando a su Majestad, que yo me había retirado de esa [Córdoba], sin rendir las cuentas del Colegio de Loreto, ni de las fundaciones del Sr. Obispo de Charcas, siendo constante lo contrario, por documentos que tenía mi sobrino Muñoz en su poder y debo suponer los llevó consigo a la corte $[\ldots] \gg .^{73}$ Sabemos que el Deán Funes no fue de los firmantes del Acta de Independencia en el Congreso de Tucumán, pero sí sabemos que estuvo allí presente. Y el grupo cordobés fue opuesto a la medida de gracia de la amnistía a Videla, por sus supuestos delitos de lesa Patria.

La sospecha de que Videla había huido a los realistas del Perú, se convirtió en un sangrante problema y profunda obsesión, tanto para Belgrano como para el Gobierno. Belgrano, aunque nada sabía sobre el paradero del Obispo, escribe así al Gobierno de Buenos Aires: «De cualquier modo que sea, hemos ganado mucho. El Cabildo Gobernador ha tomado con empeño nuestra causa, y principalmente el Deán Dr. D. Vicente Isasmendi, y con él, toda su dilatada familia, que antes, si no era contraria, al menos era indiferente». ${ }^{74}$ Por fin, todos

${ }^{72}$ AGN, Carta de Juan Ignacio Gorriti a Videla, Sala X, 4-7-2, Jujuy 18 de abril de 1816.

${ }^{73}$ ACE, Salta, Carta de Videla a D. Tomás Salustiano Gallardo sobre varios puntos referidos a la Hacienda del Colegio de Huérfanas de Córdoba, Salta, Carpeta Videla del Pino, Córdoba, 16 de febrero de 1808 .

${ }^{74}$ AGN, Carta de Belgrano al Gobierno de Buenos Aires, Sala X, 6-7-1, Jujuy 1 de junio de 1812. 
esos días aciagos desaparecieron cuando el Gobernador de Salta, comunicó al Gral. Belgrano, por carta de 4 de Agosto de 1812, «que se le presentó el Rvdo. Obispo, haciéndole llegar al lugar de su ocultación, y que con toda tranquilidad, lo restituyó a su casa, donde estaba dispuesto a cumplir el comparendo ante Vuestra Señoría, y de cuyo cumplimiento, le dijo, cuidaría. Que le ha sido muy satisfactoria esta noticia, porque temía se le huyera al enemigo, y también para que a su imitación de sujetarse a Vuestra Excelencia, se sujetan muchos del clero, contrarios a la causa de la Patria». ${ }^{75}$ Videla llevaba huido y oculto desde el 17 de abril de 1812 .

Las consecuencias, en el gobierno de la Diócesis, acordes con las aspiraciones de Isasmendi y Castro, después del destierro de Videla, no se hicieron esperar. Dentro de un bloque de cartas, con una única fecha, que parece incluye a todas, aparece una, de Isasmendi y Castro, que juzgamos de capital interés, en la que se ve claro que mantenían correspondencia habitual con el General Belgrano. Así, en una del Cabildo Eclesiástico, pero con sus únicas firmas, se dirigen a Belgrano, rogándole «tome las providencias, que sean de su resorte, y más conforme a derecho, [...], para proceder el Cabildo, con arreglo al derecho Canónico, y poder tomar en una materia de tanta gravedad, las [medidas] que exigen las presentes arduas circunstancias. Desea saber de Vuestra Señoría, si la orden de que pase su Señoría a la Capital, debe o no reputarla por una perfecta delegación o exilio, para en conformidad de la superior declaración de Vuestra Señoría, pueda activar este Cabildo, las más conducentes al mejor servicio de la Iglesia y de nuestra causa pública» ${ }^{76}$ Una primera consideración sobre el texto, es que ambos conceden a Belgrano plena capacidad jurídica en el gobierno de la Diócesis, a la que sigue o complementa su evidente deseo de anular completamente la potestad de su legítimo pastor. Ciertamente es este un verdadero golpe de estado capitular, pues dada su cercanía a Belgrano, terminarán ellos gobernando la Diócesis.

En otra carta, que se ve es contestación de Isasmendi a otra de Belgrano, dice: «Contesto a la de Vuestra Señoría de ayer, que mandaba al Reverendo Obispo a la Capital, a disposición del Superior Gobierno, para que su Excelencia determinara, lo que mejor tuviese a bien, deseoso de no tomar providencias estrepitosas, que nos condujeran al caso presente. Pero pues el expresado Reverendo Obispo ha fugado, y por toda presunción legal, debemos suponer que su fuga ha sido hacia el enemigo, Usía puede y debe tomar el gobierno del Obispado, hasta tanto que el Excelentísimo Gobierno resuelva en el particular, no teniendo ya

${ }^{75}$ AGN, Comunicación del Gobernador de Salta al Gral. Belgrano, Sala X, 6-7-1, Cuartel General de Jujuy, 4 de agosto de 1812.

${ }^{76}$ AGN, Al obispo de Salta, mientras se instruyen las causas de su destierro, Sala X, 6-7-1, Buenos Aires, 30 de Octubre de 1812 .

Hispania Sacra, LXVI

133, enero-junio 2014, 133-177, ISSN: 0018-215X, doi: 10.3989/hs.2013.049 
confianza en las manos que ha quedado [el actual Vicario Capitular], de que no sean de los mismos sentimientos, que el que los constituyó [Videla]». ${ }^{77}$

Podemos sacar de esta cita varias conclusiones de sumo interés:

- Reconocen en Belgrano pleno poder en el gobierno de la diócesis, al concederle plena capacidad legal para poner y quitar cargos, lo que denota su extremo e interesado regalismo.

- Quieren borrar toda huella de Videla y que Belgrano separe del cargo a los que puso Videla, cuando la autoridad de este continuaba vigente.

- En su carta se ven claramente sus aspiraciones a ocupar el vacío de autoridad episcopal, poniendo como aval el inapreciable patriotismo que exteriorizan.

- Muestran un total desprecio a las leyes eclesiásticas, que aquí ignoran, sustituyéndolas por el ejercicio del más extremo regalismo, con difícil ocultación de que no actúen buscando exclusivamente su propio provecho.

Pero inmediatamente después del inicio del destierro de Videla y bajo el que sospechamos claro influjo de esta carta de Isasmendi y Castro a Belgrano, Cabildo Eclesiástico y Belgrano, ahora conjuntamente, elijen Provisor Capitular al Deán Dr. D. Vicente Anastasio de Isasmendi ${ }^{78}$ es decir, la máxima autoridad eclesiástica, en sede vacante. Está claro el poder que tenía Isasmendi, apoyado en su numerosa y poderosa familia, tanto en las instituciones, como en el mismo Belgrano. La falta de clarificación definitiva de la situación militar, creemos que era otro valor añadido. Surge una pregunta: ¿toda esta actuación de Belgrano, era el tributo que tenía que pagar para asegurarse el apoyo de esta poderosa familia al sostenimiento de la causa patriótica y de su ejército? No lo descartamos. Con asombrosa rapidez el Gobierno Central comunica su aceptación del nombramiento de Isasmendi. ${ }^{79}$ Habían tenido suerte al «tocar a sede vacante», oponiéndose al legítimo Provisor, nombrado por Videla, Lic. D. Juan José Lami, y suplantándole Isasmendi. ${ }^{80}$

77 AGN, Carta de Isasmendi a Belgrano, Sala X, 6-7-1, Cuartel General de Campo Santo, 3 de mayo de 1812 .

${ }^{78}$ AGN, Carta del Cabildo Eclesiástico de Salta al Superior Gobierno comunicándole el nombramiento de Isasmendi como Provisor, Sala X, 6-7-1, Salta 16 de mayo de 1812. Llama la atención que el Gral. Belgrano envía al Gobierno Central el certificado del acuerdo que celebró el Venerable Deán y Cabildo de Salta, para tomar el gobierno del Obispado, el 6 de Mayo de 1812, cuando dicho Cabildo se reunió el 16 de Mayo, Ibídem, Sala X, 6-6-3, Campo Santo 6 de mayo de 1812. Luego Belgrano envió la comunicación antes de reunirse el Cabildo y proceder a la elección de Isasmendi.

${ }^{79}$ AGN, El Gobierno Central comunica al Gral. Belgrano el pase a la Cámara de Apelaciones del certificado del Deán Isasmendi y Cabildo de Salta para tomar el gobierno del Obispado, Sala X, 6-6-3, Buenos Aires 27 de mayo de 1812.

${ }^{80} \mathrm{ACE}$, Salta, Carta de varios presbíteros pidiendo se encarcele a Isasmendi, ACE, Salta, Carpeta querellas eclesiásticas, Salta 28 de Febrero de 1814; Ibídem, Recurso de Francisco Malbrán y Muñoz contra el destierro a Buenos Aires de Videla del Pino, Ídem. 
Videla del Pino, en cuanto se enteró de este claro atropello del derecho, escribe al Gobierno Central, protestando del «trastorno y perplejidades, que naturalmente se han seguido en la línea eclesiástica y espiritual de todo el Obispado, con la inducción de una vacante, por vía de hecho y contra derecho, removiendo aún a mi Provisor, y poniendo el gobierno eclesiástico en el Capítulo, como si yo hubiera fallecido o sido legalmente depuesto, de que resulta la ansiedad de las conciencias por la nulidad de actos jurisdiccionales $\mathrm{y}$ del fuero interno». ${ }^{81} \mathrm{Y}$ tenemos que admitir que, Videla del Pino, era muy escrupuloso en el cumplimiento de la legalidad. Prueba de ello cuando solicita, dócilmente, al Provisor de Buenos Aires, donde Videla, único Obispo entonces de las Provincias Unidas, desarrolló una intensa actividad pastoral, para que «se sirva expresarme con toda claridad, las facultades que me comete, y el territorio a que se extiende, cuyos términos observaré escrupulosamente». ${ }^{82}$

A pesar de todos estos datos, llama poderosamente la atención la cálida correspondencia que, desde el destierro, mantenían Videla y Belgrano. En contestación a una de Videla, Belgrano le dice: «me lisonjeo sobremanera de que V. S. I., se haya dignado honrarme con sus letras de 24 del pasado manifiestamente, lo que me es grato, que me tiene en su memoria delante del Santísimo, al paso que siento en mi corazón la indisposición de salud que V. S. I. padece, y que si estuviera en mis manos, remediaría, pues jamás he dejado de tener a V. S. I., las consideraciones, respetos y miramientos con soy de V. S. I. y le pido su bendición» ${ }^{83}$ ¿Qué lectura hay que hacer de esta mutua manifestación de aprecio y afecto, la política o la estrictamente literal?

\section{LUGARES DEL DESTIERRO DE VIDELA}

No conocemos el documento original en el que el General Belgrano comunica a Videla su orden de destierro. Pero son varios los documentos en los que aparece información sobre el mismo. Supuesto esto, surge la pregunta: ¿Es posible redactar un itinerario claro de los lugares donde cumplió su destierro Videla del Pino? Creemos que solamente de una forma general, con la salvedad, de que una cosa son las promesas, que recibió, de poder ir a un lugar u otro, y otra su realización.

${ }^{81}$ AGN, Carta del obispo de Salta al Gobierno Central sobre su proceso, Sala X, 4-7-2, Buenos Aires, 21 de Mayo de 1813. En esta misma carta refuta con fuerza, una a una, las acusaciones que le hacen.

82 AGN, Carta de Videla al Provisor de Buenos Aires Diego Estanislao Zavaleta, Sala X, 4-7-2, Buenos Aires 9 de octubre de 1812.

${ }^{83}$ AGN, Carta de Belgrano a Videla, Sala X, 4-7-2, Jujuy 26 de mayo de 1813.

Hispania Sacra, LXVI

133, enero-junio 2014, 133-177, ISSN: 0018-215X, doi: 10.3989/hs.2013.049 
El destierro de Videla fue decretado el 17 de Abril de $1812,{ }^{84}$ y en la misma fecha, Belgrano lo comunicó al Superior Gobierno de Buenos Aires, ${ }^{85}$ que, en vez de iniciarlo a las veinticuatro horas, como ornaba Belgrano en el decreto, Videla se ocultó, no por huir de su cumplimiento, sino porque «habiéndosele notificado la rigurosa orden de ponerse en marcha dentro de veinticuatro horas, sin tiempo para disponer de los asuntos públicos, que estaban a su cargo, ni proveerse de lo muy necesario y preciso para el dilatado viaje de más de cuatrocientas leguas, [no] [re]conociendo al señor General con facultad ordinaria ni delegada para tan violenta providencia, y que el cumplimiento de ella, era muy factible le costase la vida $[\ldots] .{ }^{86}$

Cuando decidió presentarse, tras varias semanas oculto, inició el camino hacia la Capital y al Convento Casa Grande de San Ramón Nonato de Buenos Aires. Al menos en los primeros días de Septiembre comenzaron los interrogatorios en dicho Convento de la Merced, consistentes en una larga lista, que en sucesivos interrogatorios le repetían, ${ }^{87}$ y que no terminaron en condena. Ciertamente Videla contesta a todas las preguntas que le hacen con fuerza, espontaneidad y plena seguridad, sin rehuir ninguna contestación, y rechazando todas las imputaciones con energía, por su falta de veracidad. Solamente queremos aducir una de sus contestaciones. Cuando le acusan sobre el anónimo, que envió al Marqués del Valle del Tojo, «con la cautela de haberlo acomodado en la bota del conductor o chasqui, en el que no sólo daba las noticias de nuestro estado, sino que también trataba de pintarlo débil y sin recursos, dijo que es la mayor calumnia que se le puede levantar, y que trae consigo los más notorios caracteres de serlo, así porque los indios no usan botas, como por haber escrito el declarante al marqués, por el mismo chasqui, lo contrario a la carta del Dr. Molina, que su carta, acompañada de las otras de los señores Saavedra y Molina, fue con pasaporte, y que cuando fuese capaz de una vileza como la que se le imputa, la hubiera unido con las otras, y no fiarla a un indio simple». ${ }^{88}$

Sin que se conozca la causa, el 9 de Septiembre de 1813, recibe la orden para que «dentro de tercero día, salga de esta Capital para la Punta de San Luís», ${ }^{89}$

\footnotetext{
${ }^{84}$ AGN, Carta de varios presbíteros pidiendo se encarcele a Isasmendi pidiendo se encarcele a Isasmendi, Salta, 28 de febrero de 1814, en Carpeta de comunicaciones del Gobierno.

${ }^{85}$ AGN, Acusación en forma de la Cámara de Apelaciones contra Videla, Sala X, 6-7-1, 10 de septiembre de 1813 .

${ }^{86}$ AGN, Recurso de Francisco Malbrán y Muñoz al Superior Gobierno de Buenos Aires contra el destierro de Videla del Pino, Sala X, 27-3-5, Buenos Aires 10 de junio de 1812; AGN, Recurso de Francisco Malbrán al Gobierno de las Provincias Unidas, Buenos Aires 14 de mayo de 1812, Sala X, 4. 7.2 .

${ }^{87}$ AGN, Acusación en forma de la Cámara de Apelaciones contra Videla, [...].

${ }_{88}$ Ídem.

${ }^{89}$ AGN, Carta de Videla a Belgrano, Sala X, 4-7-2, Villa de Luján, 21 de septiembre de 1813.
} 
donde había «varios confinados, y parece deben concurrir todos los prisioneros y presos por oposición a la causa. Yo necesariamente viviré inquieto y mortificado con su inmediación, temiendo por momentos alguna nueva calumnia, cuando justamente mi causa es por semejante imputación. El viaje es largo y dispendioso, el destino insoportable, por la escasez de medios para subsistir. Pido a Vuestra Excelencia se sirva destinarme a la estancia y frontera de El Tío, jurisdicción de Córdoba, lugar solo y extraviado de todos los caminos reales, pero adaptable a mi situación y pobreza, y a la comodidad que pueden desear mis aflicciones y avanzados años, o, cuando esto no pueda ser, se me destine siquiera a la Villa de la Concepción del Río Cuarto, lugar igualmente remoto y extraviado, en donde tengo un sobrino, que podrá costearme y alimentarme. Igualmente suplico a Vuestra Excelencia, se digne permitirme, que saliendo, como saldré, dentro de tercero día, me detenga en Luján a esperar la tropa, que conducirá mi familia y equipaje [...]». ${ }^{90}$ Es este un lenguaje y estado de ánimo muy distinto al que expresa en su Carta al Supremo Director, en la que «hacen cerca de cuatro meses que me hallo puesto en libertad para elegir mejor destino, favor que vive indeleble en lo más íntimo de mi corazón y me obligan a clamar todos los días al cielo por la preciosa salud, vida y felicidad y aciertos de V. Excelencia $[\ldots] \gg{ }^{91}$

D. Miguel de Azcuénaga, Gobernador Intendente de la Provincia, dio las órdenes oportunas para que «se le auxilie en los términos acostumbrados, a fin de que no quede sin efecto la voluntad del Supremo Gobierno». ${ }^{92}$ Parece que fue a Río Cuarto a donde le permitieron ir, tal como consta de una carta de sus sobrinos Ignacio Correa y Marcelino González, quienes dice que debido a no «poder saber la época fija de su salida y menos el paraje determinado a donde iba a hacer su traslación, [...], nos contuvieron a escribir antes a Vuestra Señoría Ilustrísima, hasta tener noticia de su paradero, que habiéndolo sabido hoy mismo, es el de la Concepción del Río $4^{\circ}$, en donde ha permanecido, lo verificamos ahora». ${ }^{93}$ Aquí debió permanecer hasta bastante avanzado 1817, pues es en 1813 cuando se interrumpe la documentación sobre la imposición de órdenes sagradas a eclesiásticos, que constantemente realizó en Buenos Aires, reapareciendo con nuevas ordenaciones en Diciembre de $1817 .{ }^{94} \mathrm{Y}$ fue en Buenos Aires donde falleció el 16 de marzo de 1819.

\footnotetext{
${ }^{90}$ Ídem.

${ }^{91}$ AGN, Carta de Nicolás Videla del Pino al Supremo Director de las Provincias Unidas, Sala X, 4-7-2, Villa de la Concepción de Río $4^{\circ}, 7$ de junio de 1814.

${ }_{92}$ AGN, Carta de D. Miguel de Azcuénaga, Coronel del Ejército, Gobernador Intendente de esa Provincia a Belgrano, Sala X, 4-7-2, Buenos Aires 10 de septiembre de 1813.

93 AGN, Carta a Videla de sus sobrinos Ignacio Correa y Marcelino González, Sala X, 4-7-5, Buenos Aires, 4 de septiembre de 1815.

${ }^{94}$ La mayor parte de esta abundante documentación está en ACE, Salta, Carpeta Expedientes sacerdotales.
}

Hispania Sacra, LXVI

133, enero-junio 2014, 133-177, ISSN: 0018-215X, doi: 10.3989/hs.2013.049 
¿Dónde residió en Concepción de Río Cuarto? No existen datos sobre ello, aunque por el mismo Videla sabemos que no fue, al menos siempre, un lugar confortable. En Carta al Secretario de Estado Dr. Esteban Agustín Gascón, le dice: «Recibido de caridad, en una casa de familia, poco conforme a los sagrados cánones, y reducido a una trastienda de seis varas y media, ha sido ella mi habitación, sala de recibo y oratorio. Su estrechez ha impedido el ministrar con franqueza los sagrados órdenes, a otros muchos que los solicitan. Y en cuanto a confirmaciones, me ha hecho mirar con el mayor dolor, que las gentes principales, que las han solicitado, se hallan visto obligadas a esperar de pie en el patio, y aún en la calle, pues lo reducido de dicha habitación, no permite más de veinte personas, que se oprimen e incomodan unos a otros, no menos que a mí mismo».95

\section{DOCUMENTACIÓN Y PATRIOTISMO DE VIDELA}

Es llamativo el que en toda la abundante documentación epistolar que conservamos de Nicolás Videla del Pino, de numerosas y variadas personas y personalidades, e iniciado ya el período patrio, y que a pesar de su estricto carácter confidencial, no encontramos la más mínima referencia de su inclinación por la causa realista. Y estamos hablando de cartas, de relación epistolar, en las que, si de verdad sus sentimientos hubieran sido pro realistas, dado el carácter privado de este tipo de comunicación, no cabe duda de que hubieran aflorado. De sus acérrimos detractores tenemos que afirmar exactamente lo contrario, ya que sobra documentación para poder declararlos arribistas, más que realistas.

Las expresiones que de toda esta correspondencia tenemos, suenan como «el no haber dado a esa un galope ha sido por esperar se evacue la provincia, que posee el enemigo, que en tal caso ya podremos contar con esas plazas de Oruro y La Paz», ${ }^{96}$ «nuestro ejército», «el enemigo», ${ }^{97}$ «y nuestro Gral. Rondeau, que hace días batalla, no aguardó a que se restablezca más Pezuela [...]. Han marchado al Perú con Pezuela todas las familias opuestas a nuestro sistema», ${ }^{98}$ «cerca de 200 personas, de todas clases, que escapan de la borrasca o estragos [...], pero ha sido tanta la persecución, que al enemigo han hecho nuestros paisanos o gauchos, que le obligó a aquella peste a retirarse», ${ }^{99}$ " «se dice que hay cartas que aseguran que Pezuela se mueve y que se halla en persona en Cotagasta», ${ }^{100}$

\footnotetext{
${ }^{5}$ AGN, Carta de Videla al Secretario de Estado, Sala 4-7-2, Buenos Aires 16 de octubre de 1817.

${ }^{96}$ AGN, Carta de José Félix Arias a Videla, Sala X, 4-7-2, Salta 6 de septiembre de 1812.

${ }^{97}$ AGN, Carta de Pedro Pablo Arias Velásquez, Sala X, 4-7-2, Salta 5 de mayo de 1813.

${ }^{98}$ AGN, Carta de Pedro Pablo Arias Velásquez, Sala X, 4-7-2, Tucumán 16 de agosto de 1813.

${ }_{99}$ AGN; Carta de Pedro Pablo Frías a Videla, Sala X, 4-7-2, Salta 4 de diciembre de 1814.

${ }^{100}$ AGN, Carta de su sobrino Francisco Malbrán, Sala X, 4-7-2. Córdoba 6 de abril de 1816.
} 
«yo entiendo que ni Pezuela ni nadie inquietarán ni perturbarán estos territorios, según lo está enseñando la experiencia, en largo tiempo, y guardando nosotros la debida política con los gobiernos, Congreso y Cabildos y demás autoridades de arriba», ${ }^{101}$ «el día que entró el enemigo en Jujuy, según el parte que se ha dado al Sr. Coronel Bustos, quien sale para Tucumán dentro de dos días», ${ }^{102}$ «nuestro ejército está en la inacción. Hasta ahora no tenemos la menor noticia de sus movimientos. De los enemigos nada sabemos, más que estarían atrincherados en Salta y Jujuy», ${ }^{103}$ «en días pasados, al mando de Olañeta, entraron en Jujuy [...]. Dicen que sacaron dos tapados que dejó la Serna». ${ }^{104}$

Sin duda que las citas podrían seguir, pero ya es suficiente su fuerza probativa. No se ha encontrado ninguna en sentido contrario y las hay de personas, tan allegadas a Videla, como su sobrino Francisco Malbrán y Muñoz, autor de los dos recursos que hemos citado y su abogado defensor en todo su proceso, lo que quiere decir que una confidencia política era fácil el tenerla en contra de la causa patriótica, y no la vemos.

Del mismo Videla se conserva correspondencia que avala la anterior conclusión. En carta al Cabildo civil de Santiago del Estero, le confiesa que le «es de suma satisfacción, no sólo la tranquilidad, paz y concordia con que V. S. ha celebrado el Cabildo abierto para elegir diputado a la Junta Provincial de Buenos Aires, sino también el que esta haya recaído en un eclesiástico, cuyas conducta y luces harán honor a esta ciudad y proporcionará las ventajas posibles a la Provincia, no habiendo por mi parte para que el electo Dr. D. Juan José Lami, marche cuando V. S. estime necesario». ${ }^{105}$

Lami era el Provisor y Vicario General del Obispado, nombrado por Videla, y la fecha es muy cercana a la del 10 de Mayo de Buenos Aires. Con el mismo tono optimista se dirige a la Junta de Buenos Aires: «En contestación al superior oficio de V. E. de 13 de Junio último, debo asegurar a V. E., que su Obispo de Salta, el clero, Cabildo y vecindario, han conocido muy bien el interés propio que le prepara la creación de la Excelentísima Junta Gubernativa, y no pueden desentenderse de promover cada uno, de por sí, cuanto ceda en obsequio de los excelentísimos señores que la componen, y en servicio del a quien sacrifica V. E. todos sus cuidados y desvelos» ${ }^{106}$ La Junta contestó agradecida al anterior

${ }^{101}$ AGN, Carta de su sobrino Francisco Malbrán, Sala X, 4-7-2. Córdoba 9 de abril de 1816.

${ }^{102}$ AGN, Carta de Juan José Lami, Sala X, 4-7-2, Santiago del Estero de 1817.

${ }^{103}$ AGN, Carta de Pedro Isnardi a Videla, Sala X, 4-7-2, Santiago, diciembre [ilegible].

${ }^{104}$ AGN, Carta de su sobrino Francisco Malbrán, Sala X, 4-7-2, Salta 29 de enero de 1818.

${ }^{105}$ AGN, Carta de Videla al Gobierno de Justicia y Regimiento de Santiago del Estero, Sala IX [i], Salta 20 de julio de 1810 .

${ }^{106}$ AGN, Carta de Videla a la Junta Provincial Gubernativa de Buenos Aires, Sala IX, Salta, 1 de septiembre de 1810 ,

Hispania Sacra, LXVI

133, enero-junio 2014, 133-177, ISSN: 0018-215X, doi: 10.3989/hs.2013.049 
oficio de Videla, disponiendo «se den a V. S. I., las debidas gracias, con encargo de que se procure mantenerlos en esta buena disposición». ${ }^{107}$

No es la única referencia positiva la esta Junta Gubernativa de Buenos Aires a Videla. En oficio de 12 de Mayo de 1812, dirigido al Sr. Provisor y Vicario Capitular, en sede vacante, y en referencia a la Instrucción Pastoral del Obispo de Salta, dice que «el Obispo de Salta se franquea abiertamente, y en su diócesis se observa religiosamente la indicada iniciativa», ${ }^{108}$ comunicación que contrasta abiertamente con el conocimiento que dicha Junta ya tenía de la orden de destierro dictada contra Videla por Belgrano.

\section{GOBIERNO CENTRAL Y COBRO DE LAS RENTAS POR VIDELA}

El cobro de diezmos fue un contencioso, que mantuvo permanentemente Videla con la autoridad civil. Cuando el 9 de Septiembre de 1813 recibe la orden de salir de Buenos Aires hacia la Punta de San Luís, y Videla consigue la permuten a la Villa de la Concepción de Río $4^{\circ}$, se encuentra con tal penuria económica, que va a tener que vivir de limosna. El Director Supremo había solicitado «al augusto Congreso de la Soberana Asamblea una amnistía general sobre todas las causas pendientes, y que habiéndosela concedido, se lo participaba para que regresase a esta capital a disfrutar en ella, por ahora, de la tranquilidad y satisfacciones correspondientes a su dignidad y elevado carácter». ${ }^{109}$ ¿Era una amnistía plena? No, porque la «causa se halla hasta el día en estado de sumario, no se ha sustanciado ni oído al Prelado, ni mucho menos ha recaído ni puede ya recaer por la amnistía alcanzada y publicada», ${ }^{110}$ contesta Malbrán en un oficio al Gobierno Central. Libertad provisional y sin las rentas, a que tenía derecho, y con las que poder vivir dignamente. Esto obliga a Videla a dirigirse al Supremo Director, que entonces era D. Gervasio Antonio de Posadas, para que ordene a los jueces de diezmos «de las ciudades de Santiago del Estero, Tucumán y Catamarca, que se hallan bajo el glorioso mando de V. E., me dé carta uno de ellos a buena cuenta, dos mil pesos, en atención a que en cinco años, que vivo en aquel obispado, no se ha hecho un reparto formal, en el cual debe ser mucho mayor mi haber, y que de Tarija en dicho tiempo no he recibido un medio real». ${ }^{11}$

\footnotetext{
${ }^{107}$ AGN, Carta de la Junta Gubernativa de Buenos Aires a Videla, Sala IX, Salta.

${ }_{108}$ AGN, Instrucción Pastoral del 10 de abril de 1812, Sala X, 4.7.7.

${ }^{109}$ AGN, Oficio de Francisco Malbrán al Director Supremo sobre la remisión de la amnistía dada a Videla y enviada al Consejo de Estado, Sala X, 4-7-4, Buenos Aires 15 de junio de 1814.

110 Ídem.

${ }^{111}$ AGN, Carta de Nicolás Videla del Pino al Supremo Director de las Provincias Unidas, Sala X, 4-7-2, Villa de la Concepción de Río 4º 7 de junio de 1814.
} 
En esa carta anterior, dice haber indicado a su apoderado general Francisco Malbrán, que residía en Buenos Aires, que recurriera a dicho Supremo Director «sin otro objeto que promover mis alivios». Videla ya había viajado a Villa de la Concepción del Río $4^{\circ}$, pero sin rentas. Como le piden de nuevo «traer a la vista los autos y causa, que se le hubiere formado», Malbrán contesta «que dicha causa se pasó en sus principios, por soberano decreto de la Asamblea General Constituyente, a la Cámara de Apelaciones, para que la sustanciase y pusiese en estado de sentencia. Que dicho tribunal, después de evacuar las confesiones y demás diligencia, que estimó convenientes, que sinceraban la conducta y proceder del Reverendo Obispo, la corrió en vistas al Agente, quien al cabo de largos meses, y después de despreciados varios recursos, que hizo ante la Cámara y Soberana Asamblea, contestó lo que le pareció y de cuya exposición se dio traslado al Prelado». ${ }^{112}$ Esta falta de respuesta es lo que obliga a Francisco Malbrán a pedir al Director Supremo, «se den las más estrechas órdenes y comisión solicitada, para que se le acuda con las rentas devengadas y que se devengasen, con que se pueda ocurrir a sus naturales y urgentes alimentos, gastos y empeños». ${ }^{113}$

Cabe la sospecha fundada de que una poderosa mano oculta impedía todos estos justos propósitos. Hasta del mismo Director Supremo de las Provincias Unidas, pues la contestación que le dio el Consejo de Estado, a dicho Director Supremo, sobre el oficio de Malbrán, en torno al disfrute de las rentas, que Videla merecía por la amnistía recibida, implicó una nueva consulta sobre «si el Reverendo Obispo ha sido comprendido en el decreto de amnistía, si en cumplimiento del Soberano Decreto, se le han asignado alimentos y si sus rentas y sus bienes se hallan embargados». ${ }^{114}$

La urgencia de bienes materiales, llevó a Videla a contactar con el Juez de diezmos de Tucumán, Catamarca y Santiago para que le hiciesen el envío, una vez recibieran la orden de entrega de sus rentas. Inútil esfuerzo, pues de las rentas atrasadas, «el Estado se tomó el año pasado aquí cinco mil pesos, porque no hubo apoderado de V. S. I a quien entregarlos. Y lo mismo ha tomado el dinero que había en Tucumán y Santiago». ${ }^{115}$ No obstante, el contador de diezmos D. Santiago Saravia, previno a los tres jueces de diezmos de las tres citadas ciudades, «que si podían librar o remitir con personal seguro todo lo que se le pudiese, lo hiciesen a Córdoba a poder de D. José Ramón Olmedo, apoderado de V. S. I.». ${ }^{116} \mathrm{El} \mathrm{mismo} \mathrm{Contador} \mathrm{le} \mathrm{entregará} \mathrm{«lo} \mathrm{que} \mathrm{se} \mathrm{pueda} \mathrm{cobrar} \mathrm{de} \mathrm{aquí,} \mathrm{que} \mathrm{dice}$ serán dos mil y tantos pesos». ${ }^{117}$

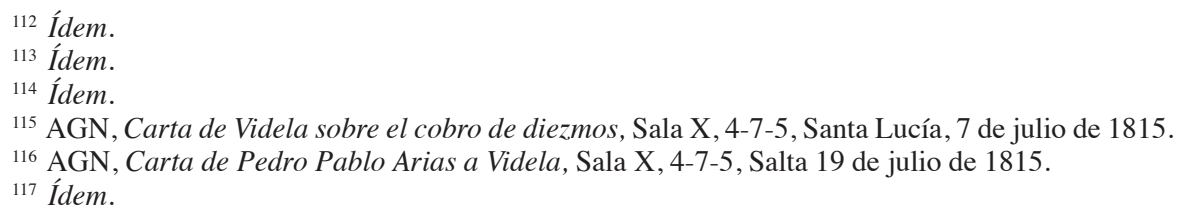


Da la impresión que si algo de estos propósitos se cumplieron fueron bien magros, ya que Martín Güemes, el 4 de Noviembre de 1817, se vio obligado a intervenir ante el Secretario de Estado del Departamento de Hacienda, urgiéndole se le abonasen «por debérsele, por sus rentas, la cantidad de diez y seis mil doscientos de renta y tres pesos y un cuartillo». ${ }^{118}$

\section{EL LABERINTO DE LA AMNISTÍA DE VIDELA}

Llegados ya al final de nuestro periplo, tenemos que reconocer que, también en el apartado de la amnistía a Videla, la suficiente y sobrada documentación que tenemos, nos introduce en un campo que parece de ciencia ficción. Hemos quizá abusado de la cita textual, pero lo hemos hecho conscientemente, para facilitar el juicio crítico del lector, y que él mismo saque sus propias conclusiones. Las nuestras están suficientemente claras y de proyección positiva. Desde Mayo de 1812 hasta el 14 de Junio de 1819, primer y último documento que poseemos sobre el tema, vamos a ver declaraciones oficiales y presunciones de sus amistades sobre su amnistía, captadas por las antenas de sus propios medios de información, de dentro o de las inmediaciones del campo oficial, que no se cumplieron.

En la primera referencia que conocemos, Hermenegildo de Echazu escribe a Videla, que «en este instante, me acaban de de decir, que este Superior Gobierno, como tan prudente, equitativo y liberal, se halla muy inclinado a la justicia de Vuestra Señoría Ilustrísima. No sé si me engañan, pero yo no lo dudo casi, a lo menos del Sr. Chiclana, porque es constante que tiene nobleza de corazón». ${ }^{119}$ Sin duda que Chiclana estaba convencido de la inocencia de Videla, pues el mismo Videla le comunica, cuando estaba a punto de iniciarse la Asamblea del Año XIII, que «una sola insinuación suya, en la actualidad, puede salvarme, y así le ruego y suplico, con el mayor encarecimiento, promueva el que se concluya, en los términos que a Vuestra Ilustrísima le parezca, sin pérdida de instantes». ${ }^{120}$ El Congresal de Tucumán por Salta, Juan Ignacio Gorriti, escribe a Videla, que «ya he mostrado a varios de los Congresales el referido documento, advirtiendo muy buena disposición en la mayor parte de ellos, y sólo hay mala

${ }^{118}$ AGN, Carta de Martín de Güemes al Secretario de Estado del Departamento de Hacienda sobre los bienes y adeudamientos a Videla, Sala IX,31-9-2, Salta 4 de noviembre de 1817.

119 AGN, Carta de Hermenegildo de Echazu al Obispo Videla, Sala X, 4-7-2, Buenos Aires 4 de mayo de 1812.Feliciano Antonio Chiclana abogado (1761-1826), participó en la resistencia a las invasiones inglesas, fue impulsor de la Revolución de Mayo, y en 1811 integró el primer Triunvirato y fue Gobernador de Salta en dos cortos períodos.

${ }^{120}$ AGN, Carta del Obispo de Salta al Gobernador Intendente de Salta Feliciano Antonio Chiclana, en Biblioteca Nacional, Leg. 316, ms. 5191, Buenos Aires, 2 de octubre de 1812. Chiclana sustituyó a Nicolás Severo Isasmendi como Gobernador de Salta, por un corto período de tiempo, cuando aquel fue encarcelado. 
prevención, en la Diputación de Córdoba. Lo sé, porque habiéndose tratado antes de mi arribo a esta, una materia, que por su incidencia se trató de Vuestra Señoría Ilustrísima, manifestaron estos diputados un empeño en acriminarlo. Sirva esto de prevención». Ya hemos hecho referencia al Deán Funes, cordobés, como Videla, y enemigo declarado suyo, quien aunque no fue de los firmantes del Acta de Independencia, sí participó en dicho Congreso.

Del año 1813, tenemos una comunicación reservada de Videla del Pino, sin fecha ni firma inteligible, en la que le comunican, que «ayer hemos recibido del Cabildo de Salta un oficio, que le hace mucho honor a su Señoría Ilustrísima, y reclama su persona, lo que le participo para su gobierno». ${ }^{121}$ Muy posiblemente este oficio del Cabildo de Salta tuviera lugar, durante la segunda y muy corta gobernación de su amigo Chiclana, durante los meses de Septiembre y Noviembre de 1813.

De Buenos Aires, y del Supremo Director Gervasio Antonio Posadas, que ya ha sido citado alguna vez, existe una comunicación a Videla, en la que le dice que «encargado por la Soberana Asamblea General Constituyente de la Dirección Suprema de las Provincias Unidas, uno de mis primeros pasos ha sido solicitar de dicha Augusta Corporación una amnistía general sobre todas las causas pendientes. Y estando ya concedidas, lo comunico a Vuestra Señoría Ilustrísima, para que se regrese a esta Capital, a disfrutar en ella, de la tranquilidad y satisfacciones correspondientes a su dignidad y elevado carácter». ${ }^{122}$ Habla de «amnistía de todas las causa pendientes», lo que implicaba que no quedaba excluida ninguna, ni la de Videla, por grave que supuestamente hubiera sido. Sabemos que no llegó a cumplirse de forma definitiva. Sin embargo, se ve que Posadas tenía fuertes motivos para esa amnistía de Videla, y en carta privada le amplía los datos: «Yo me apresuré a comunicar a Vuestra Señoría Ilustrísima la amnistía decretada por la Asamblea, a mi instancia, así porque juzgué que lo pasaría mejor en esa Capital, donde abundan más los recursos, como porque su alta dignidad no estuviera por más tiempo, sumida entre esos bosques. Pero como en aquella mi carta confidencial, siempre debió entender, a que quedaba salva e ilesa la voluntad de Vuestra Señoría Ilustrísima, para elegir lo que por bien tuviera, debe Vuestra Señoría Ilustrísima, francamente comunicarme, si destina ese u otro cualquier lugar, para su más tranquila residencia, ínterin para el rayo de la guerra por el territorio de su Obispado». ${ }^{123}$

Ya se ha visto que durante unos años vivió en Villa Concepción de Río $4^{\circ}$. Aunque por decreto tuvo que emprender el viaje inmediatamente, es posible

${ }^{121}$ AGN, Sala X, 6-7-1, Año 1813.

${ }^{122}$ AGN, Sala X, 6-7-1, Año 1813.

${ }^{123}$ AGN, Carta de Gervasio Antonio Posadas a Videla, Sala X, 4-7-2, Buenos Aires 2 de marzo de 1814 .

Hispania Sacra, LXVI

133, enero-junio 2014, 133-177, ISSN: 0018-215X, doi: 10.3989/hs.2013.049 
que este no fuera tan rápido. Su sobrino Francisco Malbrán escribió al Superior Gobierno, que «no ha podido el Reverendo emprenda el dilatado y penoso viaje, sin dinero ni arbitrios de conseguirlo». ${ }^{124}$ Aquí indica, a continuación, un destino que no eligió finalmente: «Supuesta la venia de Vuestra Excelencia, trata de trasladarse a la villa de Tulumba, también jurisdicción de Córdoba, [...], a vivir allá en casa y a expensas de su Cura Párroco el Dr. D. José Gabriel Echenique, mientras desocupada enteramente la Provincia de Salta, pueda restituirse a su Obispado». ${ }^{125}$ La causa de su pobreza estaba en que, «siendo notorio que ahora hace siete años, en que se erigió el nuevo obispado de Salta, no ha percibido rentas de aquella mitra, por las contradicciones y litigios que ha padecido la erección. Es igualmente notorio que por todo este tiempo, se ha mantenido de su patrimonio, constante en fincas, alhajas, criados y librería, de suerte que posteriores infortunios, sobre haberle arrebatado todos sus bienes, ocupados por orden del Gral. Belgrano, en términos de haberle dejado sin decencia,[...], sin que haya disfrutado en esta larga serie de tiempos, ni una asignación alimentaria, proveniente de sus rentas, así que no solamente vive incongruo, sino de socorro, como si fuera un reo privado, por sentencia de todas sus temporalidades y también de los naturales alimentos». ${ }^{126}$

Con bien fundamentados argumentos, Malbrán se refiere a lo que Videla oficialmente había solicitado: «Si por virtud de la amnistía, ha quedado fenecida su causa, [...] si es Obispo de Salta y tiene funciones episcopales, luego que cesen los impedimentos de hecho, que lo estaban, porque ya cesan y se removieron los de derecho, si ninguna sentencia le ha condenado a la pérdida de los frutos y rentas de su mitra, si de la Iglesia debe vivir y alimentarse, mientras sea Prelado de la Iglesia, nada hay más justo, como el que se le acuda con las rentas, que le corresponden de las ciudades desocupadas de Tucumán, Santiago, Catamarca y sus distritos, como también el que se le restituyan las vencidas, que no ha percibido y de que debe dársele cuenta». ${ }^{127}$ Termina dicha solicitud, haciendo hincapié en el ejercicio «que está haciendo del Patronato y protección que ejerce para con la Iglesia y sus cimientos, en orden a su dotación y conservación, se sirva mandar se le acuda con sus rentas vencidas y que vencieren en lo sucesivo». ${ }^{128}$

Nada consiguió con su brillante argumentación Malbrán. La contestación fue que «ha sido de unánime sentir, que para resolver lo conveniente, le es indispensable tener a la vista los autos seguidos contra el Rvdo. Obispo, y los demás

\footnotetext{
124 AGN, Carta de Francisco Malbrán al Superior Gobierno exponiendo pobreza extrema de Videla, Sala X, 4-7-4, 24 de mayo de 1814.

${ }^{125}$ Ídem. A esta petición contestó afirmativamente a Videla el Consejo de Estado, AGN, Sala X, 4-7-4, Buenos Aires 16 de Octubre de 1814.

126 Ídem.

127 Ídem.

${ }^{128}$ Ídem.
} 
antecedentes, que hubiere sobre el particular», ${ }^{129}$ Más aún, incompresiblemente, en nueva respuesta del Consejo de Estado a Malbrán, le dicen que «necesitan saber oficialmente, si el Reverendo Obispo ha sido comprensivo en el decreto de amnistía», de fecha 25 de Junio. ${ }^{130}$ Con fecha 23 de Septiembre, citando el decreto de 8 de Febrero del presente año, le constan también, que «sólo son comprendidos aquellos ciudadanos, que sufrían por delitos políticos o de partido, pero de ninguna manera los indicados en crímenes de lesa Patria, que esta parece ser la naturaleza de la causa del Reverendo Obispo. [...]. Este paso es necesario preceda a su restitución». ${ }^{131}$

En la comunicación de Posadas constan claramente todos los delitos, por lo que creemos que el germinal funcionamiento de las nuevas instituciones provocaba extrañas grietas e inusuales interpretaciones, en el cumplimiento de lo mandado. El problema estaba, sin duda, en la escasa duración del mandato en las Supremas Magistraturas, lo que traía, a veces, cambios ideológicos bruscos, manifiestos en el abandono de determinaciones anteriores. Una prueba de ello, la tenemos en la nueva postura positiva tomada por el Cabildo de Buenos Aires, «quien después de disuelta la asamblea y quitado los gobernantes, reasumió todas las autoridades en sí, a fin de que a V. S. I., lo restituyan a su Obispado, y fuera a descansar a Santiago, para no salir de allá jamás», ${ }^{132}$ cuando «restituido el libre goce de sus primitivos derechos, depositó su autoridad provisoriamente en este Cabildo [...], no ha podido olvidar la respetable persona de V. S. I., de cuyos trabajos se ha condolido, no pudiendo creer, a pesar de cualesquiera sospecha, que se halle mostrado indiferente a la suerte de sus hermanos, ni mucho menos atentado contra su libertad, hace a V. S. I., la justicia de suponerlo penetrado de sentimientos humanos y generosos, y le presenta la ocasión de acreditarlos, concediéndole el que pueda restituirse libremente a su silla episcopal de Salta y al ejercicio de sus sagradas funciones» ${ }^{133}$ No hay duda que esta es una clara y manifiesta amnistía, que no se cumplió tampoco. ¿Qué es lo que había producido este cambio? Felipe Frías, en carta a Videla, le dice que el Cabildo de Buenos Aires, «disuelta la asamblea y quitado los gobernantes, reasumió todas las autoridades en sí, a fin de que a V. S. I., lo restituyan a su Obispado, y fuera a descansar a Santiago, para no salir de allá jamás». ${ }^{134}$

${ }^{129}$ AGN, Dictamen del Consejo de Estado al recurso presentado por Francisco Malbrán a favor de la amnistía de Videla, Sala X, 4-7-4, Buenos Aires 11 de junio de 1814.

${ }_{130}$ AGN, Respuesta del Consejo de Estado al recurso de Francisco Malbrán a raíz de la amnistía de Videla, Sala X, 4-7-4, 15 de junio de 1814.

${ }^{131}$ Ídem.

${ }^{132}$ AGN, Carta de Felipe Frías a Videla, Sala X, 4-7-5, Buenos Aires 3 de mayo de 1815.

133 AGN, Carta del Cabildo de Buenos Aires a Videla, Sala X, 4-7-5, Buenos Aires 1 de mayo de 1815 .

${ }^{134}$ AGN, Carta de Felipe Frías a Videla, Sala X, 4-7-5, Buenos Aires 3 de mayo de 1815. 
La alegría con la que Videla recibió esta carta del Cabildo, fue indescriptible, y finalmente decepcionante, por el acostumbrado incumplimiento: «Cuanto más fluctuaba mi atribulado corazón en un mar insondable de congoja y amargura, sin poder esperar una favorable terminación a mi infortunio, dispuso el Dios de la misericordia que el mando de las Provincias Unidas, recayese en ese respetable, noble, generoso y Excmo. Cabildo. [...]. Desde el momento en que recibí la Superior Providencia de V. E., empezó a endulzarse aquel melancólico balido de mi grey, que con diligencia me buscaba, cuando yo no podía presentarme a consolarla. [...]. Mi reconocimiento y gratitud será eterna, y no desmentiré el honrado concepto, que V. E., me franquea, con mis obras, palabras y pensamientos». ${ }^{135}$

Aunque lamentablemente, no se cumplió esa orden de libertad promulgada por el Cabildo de Buenos Aires, que momentáneamente ejerció el gobierno de las Provincias Unidas, sin embargo, la obligada declaración oficial de su inocencia, que nos sigue pareciendo inevitable, podemos decir que la recibió ya, en el contenido de esta carta de dicho Cabildo al Gral. Rondeau: «Los deberes de la religión y de la justicia, unidos a la consideración de que era necesario restituir a los ciudadanos oprimidos al libre uso de sus derechos, y al goce del rango y autoridad, que los habría rebajado la intrigante preponderancia de una facción enemiga de toda persona benemérita, obligaron imperiosamente a este Ayuntamiento, no sólo a no dar crédito alguno a las imputaciones antipatrióticas, que la maledicencia atribuyó a la honorable persona del Rvdo. Padre Obispo de Salta Dr. D. Nicolás Videla, distinguido por su celo pastoral entre todos los Obispos de las Provincias Unidas, sino también a reponerlo francamente a su silla episcopal y al ejercicio de sus sagradas funciones, como un acto que creyó de rigurosa justicia, dejando al cuidado de este benemérito Prelado el allanar cualesquiera obstáculos, que por las autoridades de aquella diócesis pudieran presentársele, según se le comunicó en oficio de uno de mayo de este año. Con este motivo, y habiendo ahora manifestado su deplorable situación, interesa a este Cabildo cuanto pueda exigir de la magnanimidad de V. E., a fin de que se digne proteger a tan digno prelado, tomando al efecto todas las medidas convenientes para que venciendo todos y cualesquiera obstáculos, que se le puedan presentar al Reverendo Padre Obispo, hasta verificar su total y completa reposición a su silla, quede servido según los deseos de este Ayuntamiento, de modo que no se atrevan los ocultos émulos de este honorable Prelado, a informar, incomodar ni insultar, en manera alguna, su sagrada persona». ${ }^{136}$

${ }^{135}$ AGN, Carta de Videla al Cabildo Gobernador de Buenos Aires agradeciendo su libertad, Sala X, 4-7-5, Villa de la Concepción del Río 4º 29 de mayo de 1815.

${ }^{136}$ AGN, Carta del Cabildo de Buenos Aires al Gral. Rondeau sobre la libertad de Videla, AGN, Sala X, 4-7-5, Buenos Aires 3 de julio de 1815. 
Esta carta estaba dirigida al Gral. José Rondeau, ya que éste había reemplazado a Belgrano en 1814, quien en 1815 se dirigió al Gobernador Intendente de la Provincia de Tucumán D. Bernabé Araoz «para que se preste a S. S. I., una favorable acogida, en toda comprensión de su mando, guardándosele los fueros y respetos debidos a su alta dignidad y persona, y que interponga también los suyos, con la autoridad que corresponde, a fin de que, si las rentas del Sr. Obispo no hubiesen sido confiscadas de orden de ese Superior Gobierno, se le proporcione de ellas algún auxilio para su cómodo viaje». ${ }^{137}$

Incompresiblemente y una vez más, la amnistía decretada por el Congreso de Tucumán para todos los delitos políticos, no afectó a Videla. Juan Ignacio Gorriti, da a entender que sí, pero no lo vemos corroborado: «Me sería sumamente satisfactorio el que V. S. I., concluya y termine sus padecimientos, siendo como es invitado por el Congreso al reintegro de su silla y ejercicio de su alta y bien merecida dignidad». ${ }^{138}$ Ya presentamos, sobre el mismo tema, otra referencia de Gorriti, no muy optimista. Aquí, este congresal, lo da por hecho, con fecha un día posterior a la del memorial que Videla envió a dicho Congreso. Con firma de su Presidente, el sanjuanino Francisco Narciso de Laprida, y del Diputado Secretario Juan José Paso, se hacen eco de ese memorial de Videla, «dirigido con fecha 15 de Abril, prestando a la Soberanía de la Nación el cordial reconocimiento, fidelidad y obediencia, y comunicando su resolución a ponerse en marcha a esta ciudad. Queda enterado, y le tomará en consideración, comunicando a V. I., en oportunidad, lo que en el particular resolviese. Congreso de Tucumán, 12 de julio de 1816». ${ }^{139}$

Videla mandó un oficio a dicho Congreso de Tucumán «de reconocimiento, fidelidad y obediencia a la soberanía, ofreciendo ponerse en marcha para esta ciudad a prestarle este homenaje personalmente»..$^{140}$ Laprida, su Presidente, en la misma fecha, le dice que «le ha sido de grata aceptación la expresión de estos sentimientos, y ha resuelto se prevenga a V. S. I., verifique cuanto antes su marcha a esta ciudad, en la que tributando los debidos homenajes a la Presidencia de la Autoridad Soberana de los Pueblos, y disfrutando de sus inmediatos auspicios, tendrá V. I., la satisfacción de emplear el celo y potestad de su pastoral ministerio y dignidad a beneficio de la piadosa grey de su diócesis y necesidades de la Iglesia que lo demandan». ${ }^{141}$

${ }^{137}$ AGN, Carta del Gral. Rondeau al Superior Gobierno de Buenos Aires, Sala X, 4-7-5, Cuartel General de Mondragón, 19 de agosto de 1815.

${ }^{138}$ AGN, Carta de Juan Ignacio Gorriti a Videla, Sala X, 4-7-2, San Ignacio 16 de Abril de 1816.

139 AGN, Carta de Laprida al Obispo de Salta, Sala X, 7-4-2, Congreso de Tucumán 12 de julio de 1816.

140 AGN, Carta del Presidente del Congreso de Tucumán a Videla, Sala X, 4-7-2, Congreso de Tucumán 25 de agosto de 1816.

${ }^{141}$ AGN, Carta del Presidente del Congreso de Tucumán a Videla, Sala X, 4-7-2, Congreso de Tucumán 25 de agosto de 1816.

Hispania Sacra, LXVI

133, enero-junio 2014, 133-177, ISSN: 0018-215X, doi: 10.3989/hs.2013.049 
Una pregunta inevitable: ¿Se personó Videla en el Congreso? Creemos que no, lo mismo que tampoco se produjo la concesión de su libertad, otra vez, hecho insólito, que también contrasta con la opinión nuevamente favorable, que le manifiesta su sobrino Malbrán: «A V. S. I. se le venera y estima en Tucumán, por la pluralidad del Congreso, pueblos y vecindario [...]. Alguien dice que el Congreso despreciaba todos los informes, que últimamente se habían recibido contra Videla». ${ }^{42}$

Este ambiente favorable alimentó la idea del restablecimiento efectivo de su libertad. Sin embargo, no se conoce ningún decreto, emanado del Congreso de Tucumán, que justifique semejante impresión. Las sentidas expresiones van desde el «parabién de su perfecta restitución al alto ministerio, que dignamente ocupa» ${ }^{143}$ hasta la expresión de los más nobles sentimientos humanos y cristianos, que albergaba el corazón del héroe salteño Gral. Martín Miguel de Güemes: «Luego que regresé a esta ciudad, y sus vecinos me honraron con el empleo de Gobernador Intendente, y (hablando con mi corazón), no merezco, dediqué mis cuidados a todo aquello, que pudiese coadyuvar a los adelantamientos de una provincia desvastada. Vuestra Ilustrísima ocupó el lugar preferente, y a méritos de mis diarios esfuerzos, tuve la agradable noticia, de que ya regresaba con honor, a unirse con su Iglesia y con estos sus tiernos hijos, que le deparó el cielo. Ya proyectaba los mejores medios para facilitar su arribo, cuando he recibido la apreciable de Vuestra Señoría Ilustrísima de 20 del pasado. Ella ha conmovido mi espíritu, a pesar del gusto y satisfacción con que me hace acreedor a sus confianzas. En su contestación, ruego encarecidamente, a Vuestra Ilustrísima, se digne franquearme su voluntad, y decirme lo que necesita, para venir a ésta, seguro de que será servido con preferencia». ${ }^{144}$

Sin que se conozca la autoridad competente ni la fecha del último indulto de Videla, por el siguiente breve documento, parece que ese decreto se produjo, en cuyo supuesto, tampoco se cumplió, con la particularidad que este testimonio tiene fecha tres meses posterior al fallecimiento de Nicolás Videla del Pino, cuyo deceso se produjo, el 16 de marzo de 1819, a punto de cumplir setenta y nueve años de edad. El Director Supremo Puyrredón se interesó personalmente por las exequias, que tuvieron lugar en el destierro, en el que fue juzgado, pero no condenado, este singular ejemplar de la mejor estirpe americana.

${ }^{142}$ AGN, Carta de su sobrino Francisco Malbrán a Videla, Sala X, 4-7-2, Córdoba 31 de agosto de 1816.

${ }^{143}$ AGN, Carta de Pedro José Pelliza a Videla, Sala X, 4-7-2, Mendoza 29 de agosto de 1817.

${ }^{144}$ AGN, Carta del Gral. Güemes a Videla, Sala X, 4-7-2, Salta 14 de agosto de 1819. 
REACCIÓN DEL PUEBLO AL DESTIERRO DE VIDELA

Ya han salido varias referencias sobre el fuerte dolor con que vivió el pueblo este singular acontecimiento. Una de las reiteradas acusaciones a Videla, fue la de haber provocado intencionadamente un auténtico tumulto popular, en el momento de iniciar su primera salida de Salta. Aquí, creemos que lo que ofrecen como acusación, se convierte realmente en una clara muestra de manifestación espontánea de cariño y afecto a su Obispo. Videla contesta afirmativamente que fue a la Iglesia a rezar, «como se ordena en el Ritual Romano, que es cierto concurrió algún pueblo y lo acompañó llorando, sin el menor desorden ni tumulto, que cuando salió la segunda, evitó, con dolor suyo, esta diligencia cristiana, para no ofender la escrupulosidad del Sr. General, pero el concurso fue el mismo o mayor, acompañándole muchas gentes, hasta la primera jornada». ${ }^{145}$

Personas particulares, bien conocedoras de su inocencia, colaboraron entusiásticamente para conseguir su liberación. El Dr. Pedro Norberto de la Cerda, le escribe que el mismo Gobernador Carrera, le «significó cuan interesado se hallaba por el feliz éxito del asunto de V. S. I. Y me aseguró interpondría todo su valimiento, que V. S. I. tenía recomendaciones para con él, y que al fin, era V. S. I. un americano». ${ }^{46}$ Quizá a nivel más sencillo, Celestina Salguero le escribe que ha intentado «con tesón por sus alivios, con mi débil influjo. Hoy los repito, porque aunque ya considero a V. S. I. completamente vindicado, como me lo prometía, sé también que es llegado el tiempo de la rivalidad para los grandes hombres». ${ }^{147}$

\section{LOS HISTORIADORES OPINAN SOBRE LAS IDEAS POLÍTICAS DE VIDELA}

Traemos aquí la opinión de los historiadores que han estudiado el caso Videla, de indiscutible autoridad histórica, y contrarios a admitir como válida la grave acusación de que fue objeto paciente de ser y promover sentimientos realistas. En esta posición cobra un especial valor la repetida y dura oposición del P. Cayetano Bruno, con grave descalificación de la actitud de Belgrano, como cabeza visible de su orden de destierro contra Videla, lo mismo que de la calidad moral de Isasmendi y Castro. Como hemos ofrecido varias veces citas textuales suyas, no las vamos a repetir aquí. Pero esta opinión la consideramos muy valiosa y autorizada, por venir de historiador extraordinariamente competente, ya que es el único que ha ofrecido un amplio y bien documentado estudio sobre Videla, sin ahorrar ningún esfuerzo de pesquisa archivística. Además, su

${ }^{145}$ AGN, Juicio a Videla del Pino, Sala X, 6-7-1.

${ }_{146}$ AGN, Carta del Dr. Pedro Norberto de la Cerda a Videla, Sala X, 4-7-2, Totoral 27 de abril de 1813.

${ }^{147}$ AGN, Carta de Celestina Salguero a Videla, Sala X, 4-7-2, Salta 4 de abril de 1813. 
monumental Historia de la Iglesia en la Argentina, marca sin duda un antes y después en este campo historiográfico. Resulta agardable emitir esta opinión laudatoria, pues existe la certeza de que Cayetano Bruno no tendría ningún inconveniente en hacer suyos todos y cada uno de los planteamientos aquí expuestos. Tiene el gran valor añadido de haber corregido la opinión demasiado extendida sobre la culpabilidad política de Videla, pero lo ha hecho desde una minuciosa búsqueda archivística y conocimiento pleno de todo el material publicado. De su ejemplo deben tomar nota los que de forma irresponsablemente acrítica, se lanzan a la arena de la opinión pública, repitiendo miméticamente esas opiniones felizmente ya superadas, y apoyados en opiniones de lugares comunes, sin ninguna vigencia hoy. Sin duda que Cayetano Bruno se aparta totalmente de la que pudiéramos llamar historia oficial, refractaria a cualquier manifestación histórica que señale el lado negativo de personajes y hechos históricos.

También se han pronunciado a favor de Videla sobre su supuesta culpabilidad política, aunque parece que de forma indecisa, que denota cierta inseguridad, otros historiadores que han tratado directa y exclusivamente el tema Videla, pero no de forma completa, sino centrados en algún aspecto del mismo. Así Gabriel Foncillas, Oscar Acevedo, Pedro Grenón y Pedro S. Martínez, quienes también han iluminado caminar histórico aquí presente.

Hemos también consultado a otros autores, con opiniones negativas sobre la fidelidad política de Videla. Algunos resultan francamente desconcertantes, por provenir de auténticas autoridades en el campo de la historia argentina, con el agravante de no discriminar entre sus varias acusaciones. La referencia ahora va dirigida a la afirmación, clara y decidida, de Enrique Udaondo, en su conocido Diccionario Colonial: «No se adhirió al movimiento revolucionario de Mayo y, si bien, no se pronunció abierta y categóricamente en contra del nuevo régimen, no ocultó su disconformidad ante algunos actos producidos en el norte, bajo la responsabilidad del Vocal de la Junta, doctor Juan José Castelli, que había llegado al frente de la expedición liberadora enviada por el nuevo gobierno a las provincias del Alto Perú. Al hacerse cargo el general Belgrano del ejército del norte tuvo conocimiento de los sentimientos del obispo». ${ }^{148}$ Sobre su adhesión al movimiento revolucionario, ya se hará más adelante, y sobre la actuación de Castelli, hasta Manuel M. Alberti se pronunció, en contra del fusilamiento sumario que hizo del héroe Liniers y sus compañeros en Córdoba, y que la misma Junta de Buenos Aires, al reemplazarlo por su primo Belgrano, en este reemplazo, manifestó un claro juicio moral sobre su lamentable actuación en el Alto Perú, actual Bolivia, en contra del masivo sentimiento religioso local.

${ }_{148}$ Grenón, P. 1960. Historia, 21: 228. El trabajo se extiende hasta la página 36, con total desacuerdo en varias de sus afirmaciones. Parecen afirmaciones hechas no sobre documentación fehaciente, sino sobre supuestos, admitidos como válidos. 
Del Consejo de investigación de la Universidad Nacional de Salta, Estudio socio-económico y cultural de Salta, año 1984, se conoce la afirmación de que «al producirse el Movimiento de 1810, el Obispo se había adherido a la Junta de Mayo. Sin embargo, cuando Belgrano se hizo cargo del mando del Ejército del Norte, en marzo de 1812, dudó de la fidelidad de monseñor Nicolás Videla del Pino. Interceptó correspondencia realista donde figuraba que el obispo respondía a las autoridades españolas, por lo cual dispuso alejar a monseñor de su diócesis».${ }^{199}$ Rara y extraña mezcla de errores y aciertos en los datos y en su interpretación, destacando como completamente errónea la última afirmación, para cuya aclaración remitimos a los capítulos siguientes.

Ahora la referencia va concretamente al ya citado Gabriel Foncillas Andreu. No se pronuncia sobre el tema. Simplemente expone el motivo principal que originó el destierro de Videla, sin comprometerse claramente en su interpretación: «Transcurren los años 10 y 11 sin que ningún hecho variara la actitud de Videla del Pino, hasta abril del año 1812. Belgrano atraviesa por su Diócesis conduciendo el ejército del Norte, y tiene noticias de que el Obispo Videla, según ciertas cartas del Gral. Goyeneche - interceptadas por los patriotas - está en inteligencia con el jefe español. Aquí comienzan las andanzas del juicio inacabable que entabló el Gobierno contra el Prelado, sin que nada cierto se llegara a comprobar». ${ }^{150}$

Son afirmaciones generales, para las que no aporta ningún dato, lo que parece el mejor sistema, para que todos coincidamos en algo con el autor, pero sin que aclare nada concreto. Cierto, las preguntas que le hicieron en el Proceso, y repetidas en las diferentes visitas de los días sucesivos, siempre eran las mismas y de forma monótona y mecánica, sin que tampoco faltara la firmeza de Videla en sus contestaciones. Lamentablemente, está incompleto dicho proceso, quizá ocasionado por estar recogido en dos legajos distintos.

Pero fuera o no exacta la interpretación de Belgrano, continua afirmando Foncillas, «lo cierto es que no aparecía del todo rectilínea la conducta política del Prelado, por más que su moral fuera intachable, y sin duda no dejaría ello de contribuir a las severas medidas que se tomaron contra él». ${ }^{151}$

${ }^{149}$ Ídem. T. III, Área Histórica, Salta 1984, pág. 382. No se omiten las dudas a la hora de hacer la cita, pues no hay autor, ni clara autonomía en la división o parcelación temática y cronológica.

${ }^{150}$ Foncillas Andreu, G. 1943. «Un importante documento inédito de Mons. Videla del Pino», Archivum 1: 195-225. También escribieron sobre el asunto Tonda, A. A. 1965. La Iglesia Argentina incomunicada con Roma (1810-1858). Problemas, conflictos, solucione: 99-124. Santa Fe: Instituto de Investigaciones Históricas. Universidad católica.

${ }^{151}$ Ibídem, p. 199.

Hispania Sacra, LXVI

133, enero-junio 2014, 133-177, ISSN: 0018-215X, doi: 10.3989/hs.2013.049 


\section{El lugar del Derecho y la condena de Nicolás Videla del Pino}

En las Primeras Jornadas de Historia de la Iglesia en el NOA, celebradas en Salta los días 12 al 14 de octubre de 2006, de cuyas ponencias tenemos una selección de trabajos reunidos en el tomo Para una historia de la Iglesia. Itinerarios y estudios de caso, entre otros trabajos, tenemos una notable aportación sobre El proceso a Mons. Nicolás Videla del Pino por alta traición, y otro de Ignacio Martínez, El general, el obispo y sus «émulos». Conflictos de intereses y jurisdicciones en la diócesis de Salta durante la revolución..$^{152}$ Ambos ofrecen conclusiones ciertamente fundamentales y que van incluidas aquí.

La tesis de Ignacio Martínez se podría resumir así, usando sus propias palabras: «Los avatares vividos por el primer obispo de salteño a comienzos del período revolucionario fueron, desde un principio, objeto de estudio de la historiografía argentina. En los relatos tradicionales de la versión liberal, la interpretación coincidía sustancialmente con la óptica de las autoridades civiles que habían dispuesto su separación de la diócesis: el obispo era culpable de mantener correspondencia con los líderes en el Alto Perú, por lo tanto, quedaba sujeto a los rigores de las normas que legislaban sobre traición. El comportamiento del prelado no era de extrañar y cerraba perfectamente con la lógica de este relato. Los tres obispos habían demostrado [Lué, Orellana y Videla], de una manera u otra, una actitud contraria a la revolución.

A esta versión «acrítica» de la historia (acrítica, en la medida que no cuestionaba la interpretación ofrecida por las mismas fuentes), se enfrentó una corriente historiográfica que podríamos llamar «confesional», comprometida explícitamente con la defensa del rol jugado por la iglesia en la historia patria. Desde esta óptica, el confinamiento del obispo y su separación de la diócesis constituían una más de las tantas intrusiones del poder laico en el ámbito eclesiástico. La decisión de Belgrano de declarar vacante la diócesis salteña es denunciada por estas versiones como una medida tomada al margen de toda legitimidad jurídica, y lesiva de las tradicionales prerrogativas eclesiásticas. En este sentido, la autoridad revolucionaria aparece ampliando las dimensiones del poder secular, que avanza a partir de aquí en terrenos que, si bien la monarquía española había explorado, nunca había conquistado de modo tan decidido». ${ }^{153}$

Ignacio Martínez plantea una serie de hipótesis para explicar el problema del destierro de Videla, que nos parecen francamente interesantes, aunque

${ }^{152}$ Martínez, I. 2008. El general, el obispo y sus «émulos». Conflictos de intereses y jurisdicciones en la diócesis de Salta durante la revolución, en Caretta, G. - Isabel Zacca, I. (Comp.), Para una historia de la Iglesia. Itinerarios y estudios de caso, CEPIHA, Universidad Nacional de Salta, 2008: 194-213.

153 Martínez, I. 2008: 214-215. 
siempre nos queda la insalvable incógnita de si la normativa y recursos jurídicos que utilizaron para justificar el destierro definitivo de Videla, eran reales o fueron simplemente una sofisticada tapadera para intentar con apariencia, lo que jurídicamente era inaceptable. Pero no desaparece el convencimiento de que su destierro definitivo no lo causó el supuesto delito de grave traición, sino la necesidad que el poder civil tenía, en aquellas de auténtica singularidad histórica, de anular todo poder eclesiástico autónomo, que escapara a su exclusivo dominio civil.

También existe un parcial acuerdo con su otra opinión de que «en la decisión inicial de confinar al obispo se combinaron los intereses de sus enemigos locales, con la necesidad de los líderes del ejército del Norte de ganarse la adhesión de la élite salteña». ${ }^{154}$ Se afirma que parcialmente, porque los únicos enemigos públicos locales que aparecen en la documentación como tales, son exclusivamente los dos referidos: el Deán Isasmendi - arropado por su poderosa familia - y el canónigo Castro e incluir íntegramente en estos a «los intereses de sus enemigos locales [...] con la necesidad de ganarse la adhesión de la élite salteña», nos parece excesivo: Por la grave conmoción que causó - Belgrano intentó conjurarla con sus dos bandos-, lo que podía provocar el grave riesgo, ciertamente no impredecible, de que la élite local se quedara sin ningún apoyo popular, y si este faltaba, la experiencia negativa del jacobinismo de Castelli se podía extender por todo el NOA, con su inevitable retraso del triunfo de la armas patriotas en esta área vital.

También es aceptable sólo parcialmente su explicación sobre el destierro definitivo de Videla, cuya «prohibición de retornar a su diócesis impuesta al obispo, sebe ser explicada considerando no sólo el contexto social preexistente en Salta, sino también una serie de factores generados por la revolución, que transcienden las fronteras locales». ${ }^{155}$ Aceptando su formulación general, creemos que necesita ser explicada pormenorizadamente, sobre todo la primera, pues ese pretendido «contexto social» pudiera ir más en contra que a favor. Volvemos a recordar los dos bandos de Belgrano al pueblo de Salta, que denotan un grave nerviosismo en él, pues si su decisión gozaba al menos del apoyo de las élites, no hay motivo para publicar dos bandos prácticamente seguidos y con un lenguaje muy descalificativo para Videla, con el que sin duda intentaba reducir su indiscutible popularidad. Las apelaciones patriótica y jurídicas de Belgrano en sus dos bandos es necesario también interpretarlas bajo el prisma de los dos recursos de Francisco Malbrán, en el las grande apelaciones de Belgrano quedan seriamente debilitadas o anuladas incluso.

\footnotetext{
154 Martínez, I. 2008: 216.
}

155 Martínez, I. 2008: 216. 
El trabajo del Prof. Levaggi está centrado específicamente sobre El proceso a Mons. Nicolás Videla del Pino por alta traición, aspecto este en el que el Dr. Levaggi se mueve con verdadera destreza y auténtica comodidad. Hay disconformidad sin embargo con la opinión que sirve de encabezamiento a su excelente trabajo: «La historiografía dijo ya casi todo cuanto podía decirse acerca del proceso seguido en los años 1813 y 1814 contra el primer obispo de Salta por sospechas de connivencia contra los realistas». ${ }^{156}$ Sus mismas aportaciones en este breve pero denso trabajo, son un pequeño mentís a su anterior afirmación.

Abelardo Levaggi ofrece interpretaciones de estricto contenido jurídico que confirman lo que desde fuera de la ciencia jurídica aquí se ha afirmado: una cosa eran las proclamas oficiales de la Revolución y otra muy distinta su plasmación real. Por eso afirma que «el programa de la revolución de Mayo, que incluía el principio de la separación de poderes, plasmado en el reglamente del 22 de octubre de 1811, a cuyo tenor «el poder judicial es independiente, y a el sólo toca juzgar a los ciudadanos» (III), era negado en la práctica. La anomalía se repetía desde 1810, pero la Asamblea, al identificarse con la soberanía misma, producía la mayor concentración del poder imaginable, con la consiguiente negación de las garantías individuales, proclamadas en el decreto de 23 de noviembre». ${ }^{157}$ Esto provocó el que la Asamblea se reservase el dictado de la sentencia, comisionando a la Cámara de Apelaciones, sucesora de la Real Audiencia, la sustanciación del proceso y acusación. La intervención de un tribunal secular en el juicio a Videla era legal. Lo que no era legal era que en un cuerpo político, la Asamblea se arrogase la función judicial.

En principio el fuero del obispo era eclesiástico y debía ser juzgado por sus tribunales. Pero la acusación que se le hacía - de alta traición - era un delito incluido en «los casos de corte», que provocaba su desafuero y consiguiente sometimiento a la justicia ordinaria, por ante sus tribunales superiores. En

${ }^{156}$ Levaggi, A. 2007: 1. Si la historiografía lo hubiera dicho ya casi todo y ese todo fuera conocido entre los historiadores, no sería fácil que en la actualidad se hicieran afirmaciones como la siguiente: «Hizo su entrada [en Salta] en 1808, pero se vio envuelto en todo el proceso emancipador, manifestándose netamente realista. Refugiado en el convento de La Merced, donde vivó medio preso, luego fue recluido en la villa de la Concepción del Río Cuarto bajo vigilancia policial, de donde logró evadirse y regresar a Buenos Aires, nuevamente al convento de La Merced, donde pasó los últimos años de su vida. Murió en Salta el 17 de marzo de 1819», SANTOS, A. 1992. El Plata: La Iglesia diocesana (I), en Borges, P. (director), Historia de la Iglesia en Hispanoamérica y Filipinas (Siglos XV-XIX), vol. II, Madrid: BAC. Con el mayor respeto hay que decir que es muy difícil escribir más errores en tan corto párrafo. Y es que con la escasez bibliográfica que usa, no es fácil que pudiera escribir algo mejor, ya que se basa exclusivamente en la conocida obra de Egaña, A. de. 1966. Historia de la Iglesia en la América española desde el descubrimiento hasta comienzos del siglo XIX. Hemisferio Sur, Madrid: 726-737.

${ }^{157}$ Levaggi, A.: 2007: 6. 
este sentido la intervención de un tribunal secular era legal. Lo que no era legal, era que un cuerpo político, la Asamblea, se arrogase la función judicial. ${ }^{158}$

Levaggi se suma a la acertada opinión del P. Arsenio Seage quien termina afirmando que finalizó así «el largo y penosos destierro que le impusieron las autoridades civiles, que nunca pudieron probar su culpabilidad ni quisieron dictar sentencia final». ${ }^{159}$

No queremos omitir las valiosas conclusiones a las que llegó Abelardo Levaggi en el estudio a que aquí nos referimos. Y lo hacemos citándolo de forma literal:

1. Las dudosas sospechas de traición a la causa americana, que desde 1812 recayeron en Mons. Videla del Pino, provocaron su desgracia por el resto de sus días.

2. La primera desgracia fue su precipitado destierro de Salta, para presentarse en calidad de reo ante el gobierno de Buenos Aires, son gozar de los beneficios del decreto de seguridad individual.

3. Constituida en juez suyo la Asamblea General Constituyente, quedó privado de ser juzgado por un tribunal independiente. La Cámara de Apelaciones solamente actuó como comisionada de aquella.

4. Sometido en el primer año de su detención a una prisión rigurosa, pese a sus setenta y dos años, es decir, tratado como reo de delito atroz, le fue extendida de a poco la carcelería, más sin haber logrado nunca la plena libertad.

5. El proceso que se le siguió fue sumario y no salió nunca de ese estado. Las únicas pruebas admitidas fueron las aportadas por la acusación. El prelado no tuvo la oportunidad de ofrecer y producir contrapruebas.

6. Dichas pruebas, como lo puso en evidencia el propio fiscal, fueron insuficientes para demostrar su culpabilidad, y debieron ser forzadas para mantener la sospecha.

7. Pese al reconocimiento de la debilidad probatoria, de que el juicio estaba «imperfecto e insustanciado», el fiscal se basó en la supuesta sospecha para pedir que se le aplicase una pena extraordinaria.

8. La causa se suspendió de hecho con el traslado de la acusación y nunca más fue impulsada, no obstante lo cual el obispo fue tratado como reo, privado de la libertad de movimiento, impedido de regresar a su sede.

9. El juicio adoptó, pues, las formas más estrictas del procedimiento inquisitivo de la monarquía absoluta, desconociendo los derechos y garantías liberales proclamados desde $1810 .{ }^{160}$

${ }^{158}$ Levaggi, A. 2007: 6.

159 Seage, A: 1980: 47.

${ }^{160}$ Levaggi, A. 2007: 24. Todo este apartado es cita textual de la obra citada. 
Habría que añadir, siguiendo a Abelardo Levaggi, que Videla del Pino no tuvo oportunidad de presentar pruebas en contra de las acusaciones que le hicieron, porque no le dejaron. Las únicas pruebas que fueron presentadas, en el supuesto de considerarlas como tales en sentido amplio, fueron los múltiples testimonios que recibió de los auténticos patriotas. Y de estos hemos presentado más que suficientes en este trabajo.

\section{CONCLUSIÓN}

Alcanzado el final de este trabajo, la opinión final es que no es posible acusar al primer Obispo de Salta, Dr. D. Nicolás Videla del Pino, de haber sido ni espía, ni colaboracionista de los realistas, ni tampoco de haber vivido los acontecimientos que germinaron a la Patria, con sentimientos y contactos con los realistas. La prueba definitiva está en que fue juzgado en un severo proceso, no fue condenado al no haber sido encontrado culpable, y sin embargo, no fue puesto en libertad, a pesar incluso de las varias amnistías concedidas, muriendo en consecuencia en el destierro. Lo que sí parece claro es que siempre vivió su trabajo episcopal con una fuerte vocación y total entrega a su misión pastoral, tanto en Asunción del Paraguay primero como en Salta después, y finalmente en Buenos Aires, donde ostentó la exclusiva episcopal, no sólo de las Provincias Unidas, sino incluso, en algunos momentos, de todo el antiguo Virreinato del Río de la Plata, junto con Chile. Se deduce, porque de todos esos lugares le solicitaron y confirió en Buenos Aires las órdenes sagradas a los solicitantes.

En honor a la verdad, hay que decir también, que en los inicios patrios hubo comportamientos negativamente graves, que en nada estimulaban la adhesión a la causa patriótica. Ya se ha aludido a la campaña de Juan José Castelli en el Alto Perú, a la que ahora se añade, el sumario fusilamiento de Liniers y de los casi treinta oficiales realistas en Cabeza del Tigre, provincia de Córdoba, ordenado también por Juan José Castelli, primo de Belgrano y abogado como él, fusilamiento del que al obispo de Córdoba, Rodrigo Antonio de Orellana, le libró la sotana. ¿Tan pronto se le había borrado el agradecimiento, que todos profesaban a Liniers, por haber sido el héroe que libró a las Provincias Unidas de las invasiones inglesas? Castelli sí se había olvidado, pero otros patriotas, como Manuel Alberdi no, que se manifestaron muy disconformes con este acto de clara, innecesaria e inmisericorde crueldad. Estos hechos, tenían que provocar perplejidad en espíritus rectos y nobles, como el de Videla del Pino. A pesar de estas quizá inevitables y sin duda inaceptables conductas, un análisis desapasionado de los documentos transcritos, hablan elocuentemente de su inocencia, y si en algún momento inicial pudo ser políticamente posibilista, en conjunto las características de su comportamiento, son inconfundiblemente patrióticas, presididas por un ejemplar criterio pastoral y profundo sentido de Iglesia. 
BIBLIOGRAFÍA
AAC:
Archivo del Arzobispado de Córdoba
ACE de Salta:
Archivo de la Curia Eclesiástica de Salta
AGI:
Archivo General de Indias
AGN:
Archivo General de la Nación,
ASV:
Consultor, años 1802/1803, fol. 306v
ASV:
Processus consistoriales, vol. 208, ff. 391ss.
ASV:
$F c-A c$.

Caretta, G. y Zacca, I. (Comp.). 2008: Para una historia de la Iglesia. Itinerarios y estudios de caso, CEPIHA, Universidad Nacional de Salta: 194-213.

Bruno, Cayetano. 1971. Historia de la Iglesia en la Argentina, vol. VII: 160. Buenos Aires: Editorial Don Bosco.

DellaFerrera, N. 1996. Los Provisores de la Iglesia de Córdoba, Separata de Cuadernos de Historia, $\mathrm{N}^{\circ}$ 6, Córdoba.

Egaña,A. de. 1966. Historia de la Iglesia en la América española desde el descubrimiento hasta comienzos del siglo XIX. Hemisferio Sur: 726-737. Madrid: La Editorial Católica.

Foncillas Andreu, G. 1943. «Un importante documento inédito de Mons. Videla del Pino», Archivum 1: 195-225.

Grenón, P. 1960. «Episodios de lucha interna». Historia 21: 228.

Levaggi, A.2007. «El proceso a Mons. Nicolás Videla del Pino por alta traición». Épocas, Revista de la Escuela de Historia, Usal, 1: 37-65.

Martínez, Pedro S.1961 «Mons. Nicolás Videla del Pino. Noticias acerca de su vida, obra y actitud frente a la Revolución», Archivum V: 353.

Martínez, I. 2008. El general, el obispo y sus «émulos». Conflictos de intereses y jurisdicciones en la diócesis de Salta durante la revolución, en Caretta, G. y Zacca, I. (Comp.), Para una historia de la Iglesia. Itinerarios y estudios de caso: 194-213, Universidad Nacional de Salta: CEPIHA.

Ritzler, Remigium, R. - Pirminium, S. 1968. Hierarchia Catholica, vol. 7: 330. Patavii: Typis et Sumptibus Domus Editorialis «Il Messaggero di S. Antonio» apud Basilicam S. Anton.

Sánchez Pérez, E. 2011. Nicolás Videla del Pino primer obispo de Salta. Documentación Archivística: 771. Salta: Arzobispado de Salta - Servicio de Publicaciones.

- 2012. Las exigencias políticas de la Emancipación. Nicolás Videla del Pino. Primer Obispo de Tarija con sede en Salta 1807-1819: 258. Sucre: Fundación Cultural del Banco Central de Bolivia.

Santos, A. 1992. El Plata: La Iglesia diocesana (I), en Borges, P. (director), Historia de la Iglesia en Hispanoamérica y Filipinas (Siglos XV-XIX), vol. II, Madrid: Biblioteca de Autores Cristianos.

Hispania Sacra, LXVI

133, enero-junio 2014, 133-177, ISSN: 0018-215X, doi: 10.3989/hs.2013.049 
Seage, A. 1980. Tavella, primer Arzobispo de Salta, t. I Escritos, Salta 1980, pág. 212.

- 1946. Conferencia pronunciada en la Junta de Estudios Históricos de Mendoza, el 12 de Octubre de 1946, y publicada en el Boletín del Instituto de San Felipe y Santiago de Estudios Históricos de Salta 18.

Toscano, J. 1907. El primitivo obispado del Tucumán y la iglesia de Salta. Impr. de M. Biedma. Digitizing sponsor: GoogleBook from the collections of: Harvard University. dentifier-access: http://www.archive.org/details/elprimitivoobis00toscgoog.

Tonda, A. 1965. 1965. La Iglesia Argentina incomunicada con Roma (1810-1858). Problemas, conflictos, solucione: 99-124. Santa Fe: Instituto de Investigaciones Históricas. Universidad Católica. 